Journal of Al-Azhar University Engineering Sector

Vol.16, No. 59, April 2021, 463-478

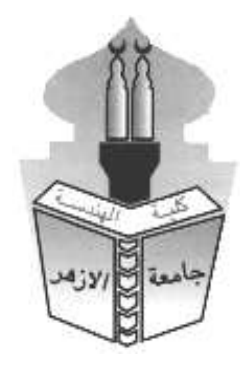

\title{
THE EFFECTIVENESS OF APPLYING THINKING SKILLS AND ITS TOOLS IN TEACHING ART AND ARCHITECTURE HISTORY COURSES FOR THE BA STAGE (AN APPLIED STUDY FOR STUDENTS OF THE COLLEGE OF DESIGN AND ART IN JEDDAH)
}

\author{
Reem Farouq Hassan Alsabban \\ Interior Design department, Collage of Art \& Design,University of Jeddah, Jeddah, KSA.
}

\begin{abstract}
Islamic architecture teems with marvels created by scholars and architects throughout history, and these landmarks are still subject of study in today's age. Indeed, the methods teachings of these scholars have made it to university courses around the globe. Local universities in Saudi Arabia have also added these architectural heritage sites to their curriculums, aiming to enrich the identity of the new Muslim architect. However, when looking at the histories of past Muslim cultures, their prevalent architectural elements, the factors that affected them, and the Islamic expansion into their surrounding continents, we find that Islamic architecture has elements that carry across eras, but they take on unique traits. These unique traits could be attributed to the influence the new lands and their cultures had on architects to create such lasting effects to this day. Students learning about Islamic architecture, the author of the paper noted in her time teaching university students, have difficulty distinguishing between the architectural elements of different eras and cultures. This paper aims to provide a method for students of architecture to organise their observations in such a way as to better recall architectural elements and their contexts. This method builds students' critical thinking skills through thinking tools such as mind maps and visual notetaking (Sketchnoting). This paper uses descriptive analytical methods and experimental methods, as the author has conducted a study on a group of students in the course "History of Art and Architecture 2 (Islamic Architecture)" in the department of art in design in the years 2016, 2017, and 2018. The results of this study show that students have a higher capacity to retain information using critical thinking tools, and the paper provides recommendations regarding the development of the methods used to teach students in university-level art and architecture courses.
\end{abstract}

Keywords: Islamic architecture- Design - arts- Sketch noting- mind maps interior design 


\section{فاعلية تطبيق مهارات التفكير وأدواته في تدريس مواد تاريخ الفن والعمارة لمرحلة البكالوريوس

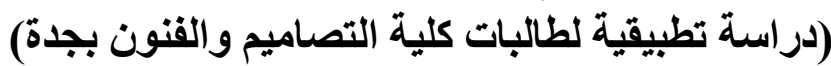

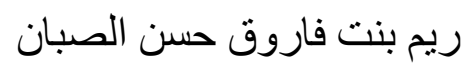

قسم التصميم الداخلي، كلية التصاميم والفنون، جامعة جدة، جدة، المملكة العربية السعودية.

يزخر تاريخ العمارة الإسلامية بكنوز عظيمة بنيت وشيدت من قبل مهندسين و علماء عرب ومسلمين، وقد تهافتت

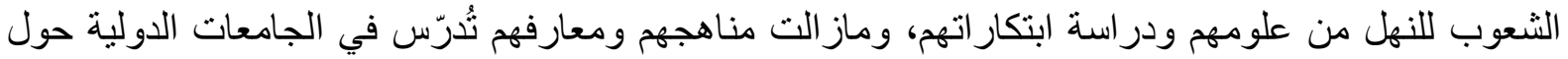
العالم حتى وقتنا الحالي، وقد تضمنت مناهجنا في الجامعات المحلية لكليات الهندسة و والتصاميم بارئ بالمملكة العربية

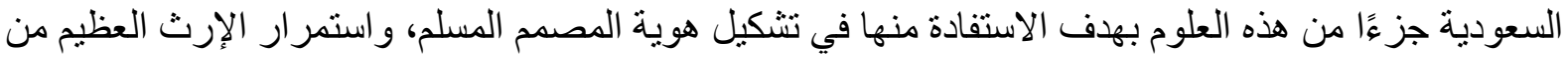

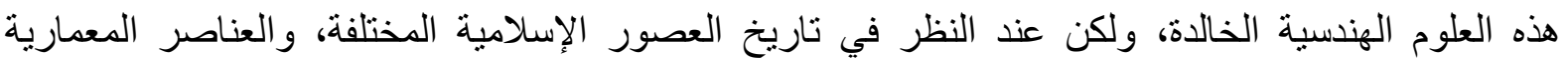

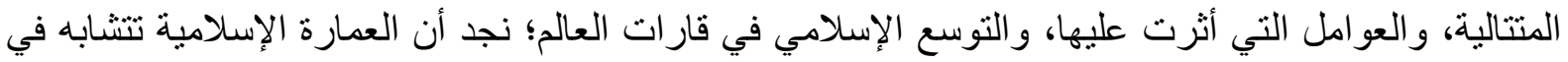

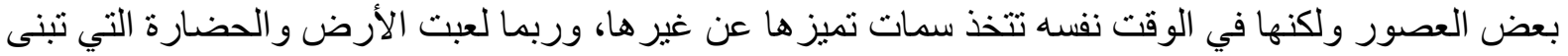

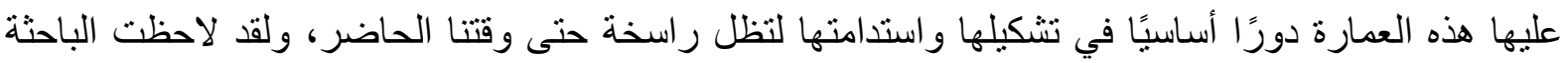

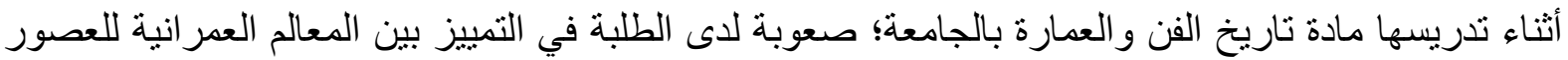

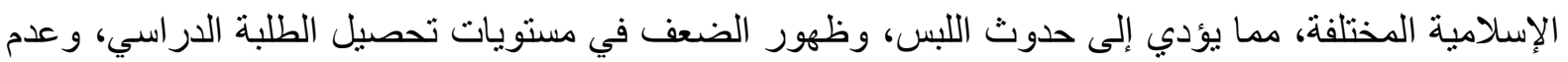

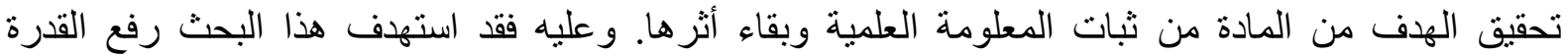

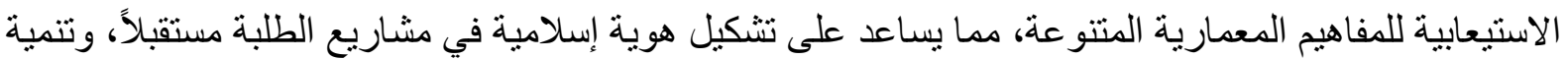

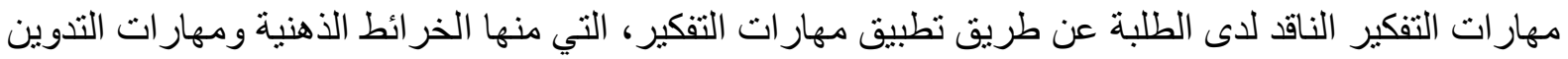

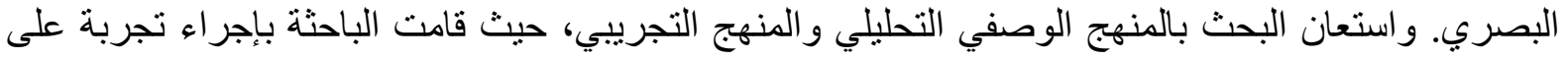

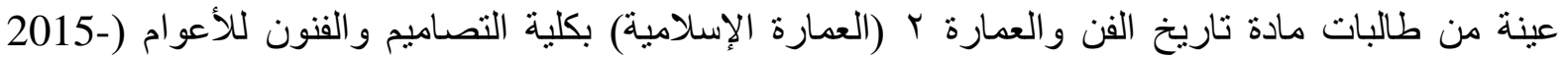

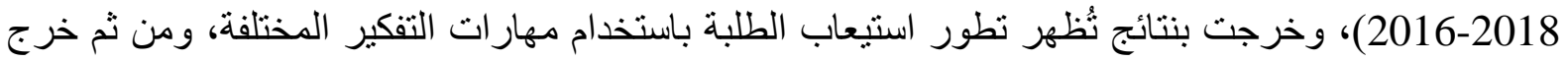
البحث بتوصيات في تطوير طرق تدريس مو اد تاريخ الفن و العمارة بالجامعات.

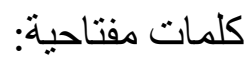

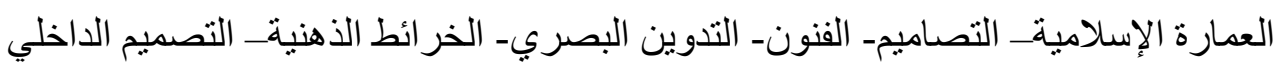


"التفكير سمة من السمات التي تميز الإنسان عن غيره من المخلوقات الأخرى، فهو نشاط عقلي متأمل وهادف

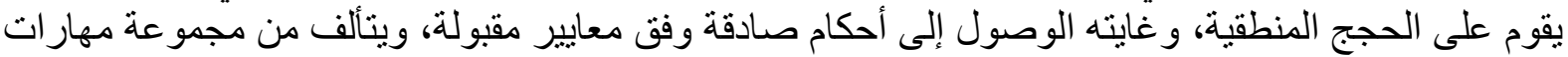

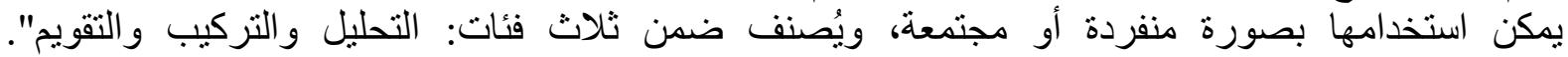

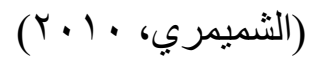

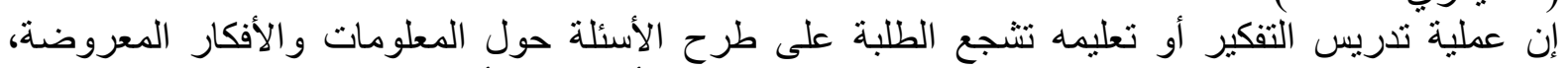

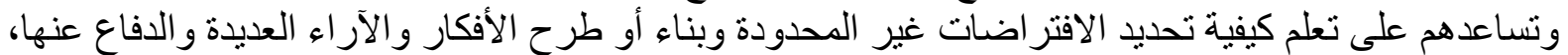

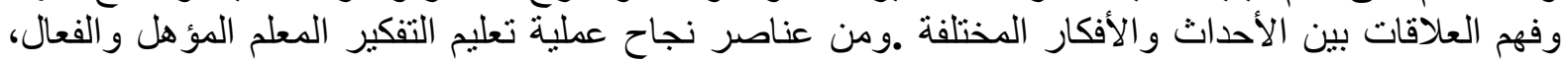

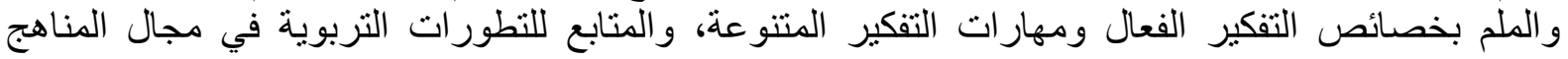

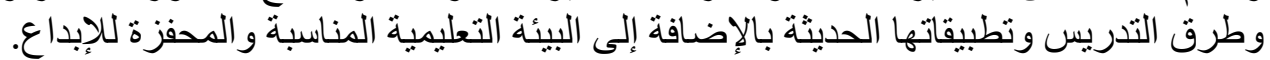

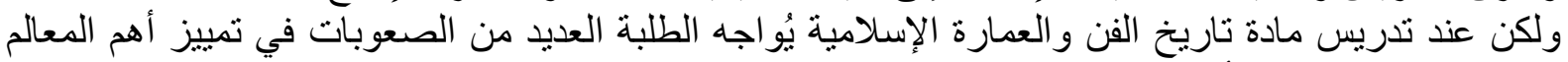

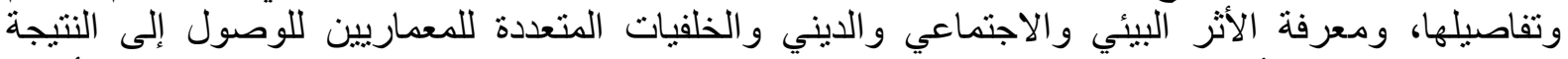

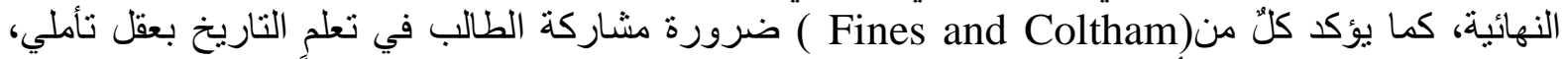

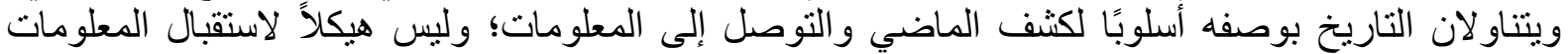

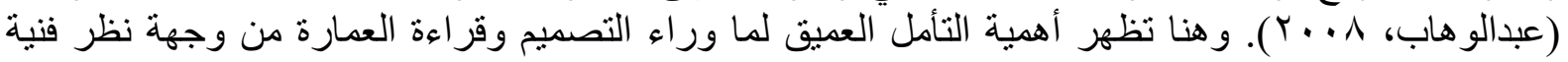

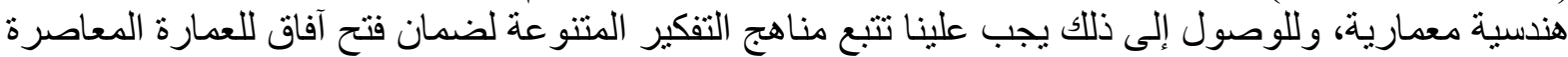

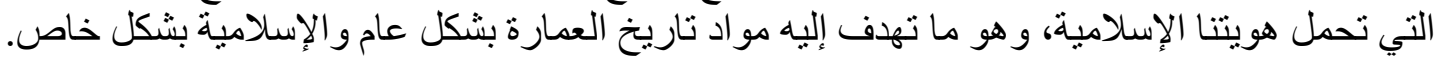

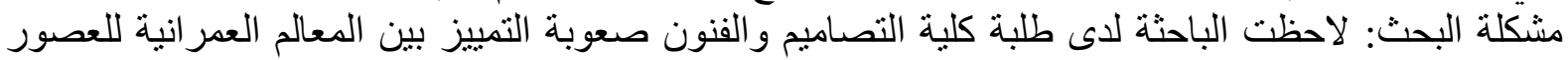

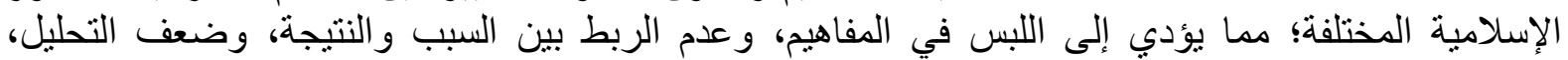
و انخفاض في درجات الطلبة، و عدم ثبات المعلومة العلمية وتحقيق الهدف من المادة وبقاء أثرها؛ ومن هنا ظهر

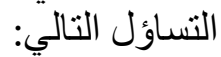
ما مدى فاعلية تطبيق مهار ات التفكير و أدو اته في تدريس مو اد تاريخ الفن و العمارة لمرحلة البكالوريوس؟

\section{أهداف البحث: \\ تنمية مهار ات التفكير الناقد لدى الطلبة.

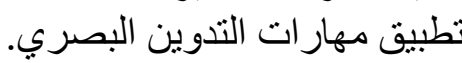

رفع القدرة الاستيعابية للمفاهيم المعمارية المتنتوعة، مما يساعد على تشكيل هوية إسلامية في مشاريع الطلبة مستقبلاً.

منهجية البحث: يتبع هذا البحث المنهج الوصفي و المنهج التجريبي.

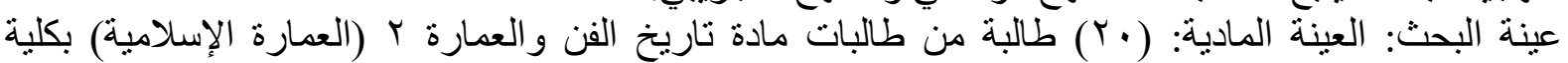

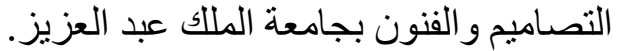
العينة الزمنية: الأعوام الدراسية التالية.(2015 -2016 -2018) :

$$
\begin{aligned}
& \text { أدوات البحث: } \\
& \text { عرض صور ووثائق. } \\
& \text { عرض فيديو هات وتحليلها. } \\
& \text { استخدام تقنيات العالم الافتر اضي. } \\
& \text { لوح الفصل و أقلام ملونة. }
\end{aligned}
$$

1- المحور الأول: التفكير ومهاراته:

يُعرّف ويلسون التفكير Y Y Y . . Filson) ) بأنها "عملية عقلية يتم عن طريقها معرفة الكثير من الأمور وتذكر ها وفهمهاو وتقبلها".

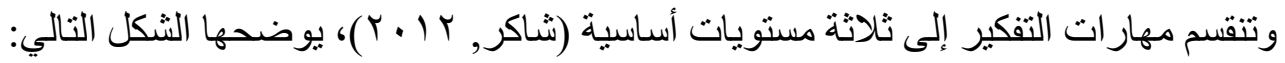




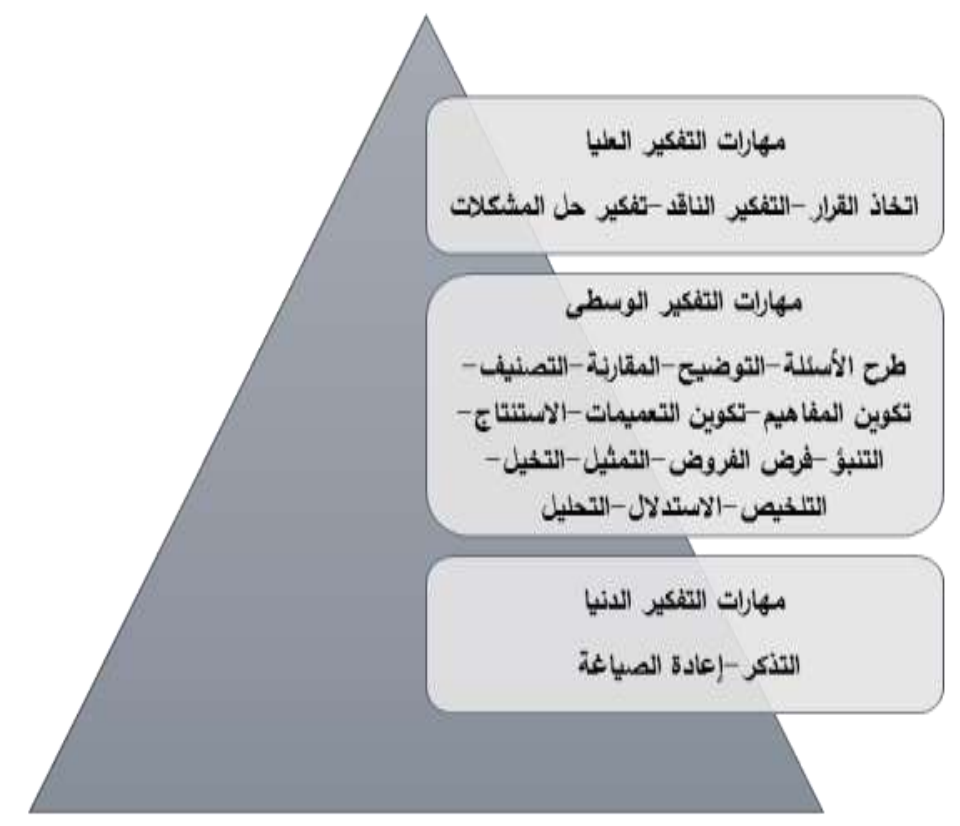

شكل(1 ) : يوضح مستويات مهارات التفكير

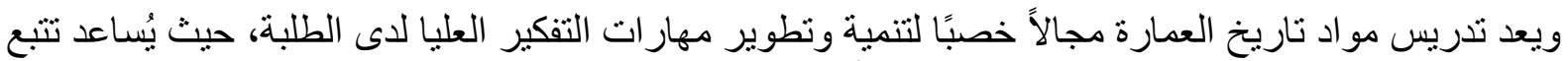

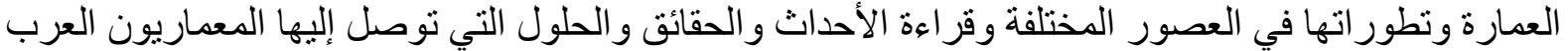

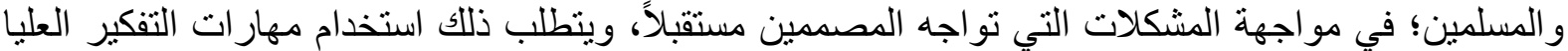
من خلال تدريب الطلاب على استخلاص الحقائق، واتباع أساليب الاستقصاء، والبحث و وعليات التحليل

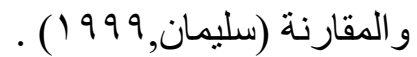
وبحسب تصنيف فيشر توجد أنماط عديدة للتفكير، حيث اقترح تصنيفًا لمهار ات التفكير الأساسية على أن نشمل الآتي: مهار ات تنظيم المعلومات ـ مهار ات الاستقصاء ـ المهار ات ذات العاتلاتة بالمبرر ات وات والأسباب ـ مهار ات التفكير

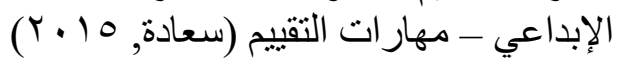

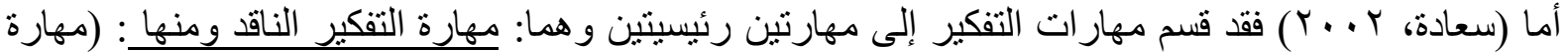

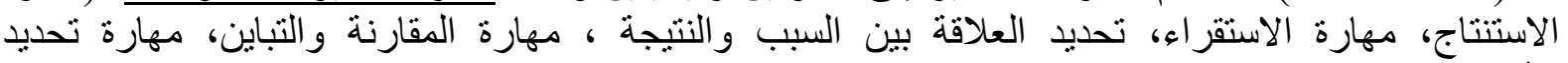

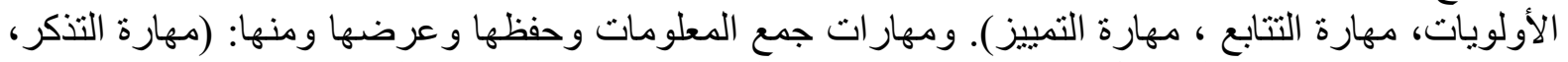

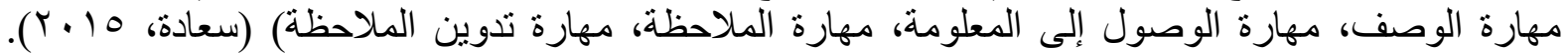
وحسب التصنيف السابق لـ (سعادة , . . . اللتفكير الناقد فقد تبنى البحث الحالي بعض مهارات التفكير الناقد ومهار ات تتظيم المعلومات.

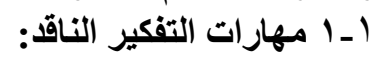
عرف باير ( beyer, 19 (1 ) التفكير الناقد بأنه "ذلك النوع من التفكير القابل للتقييم بطبيعته، والمتضمن

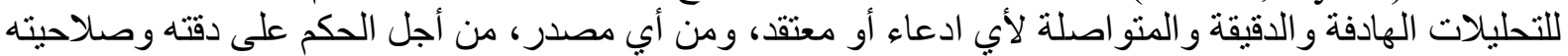

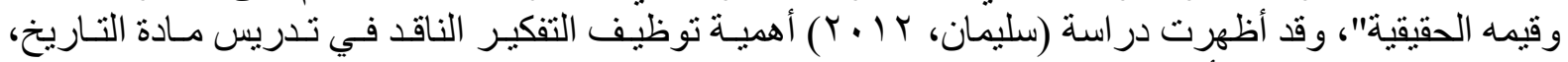

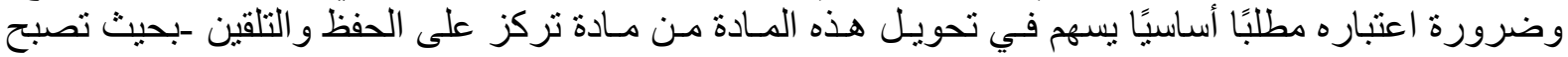

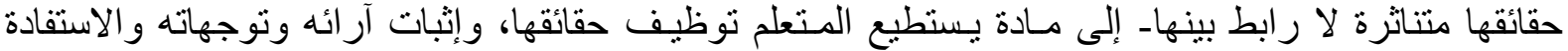

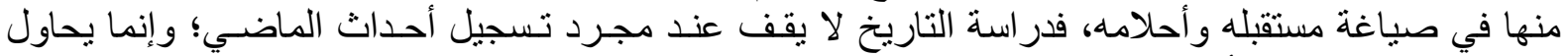

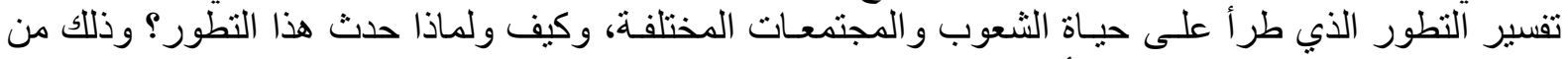

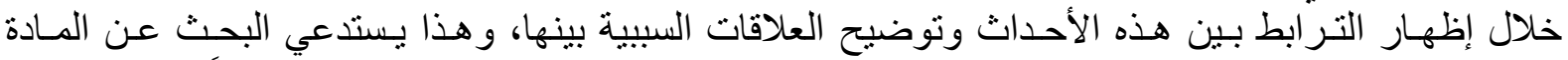

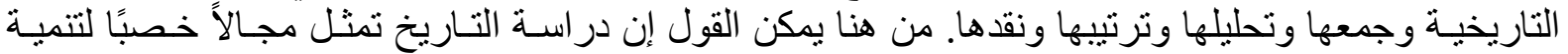

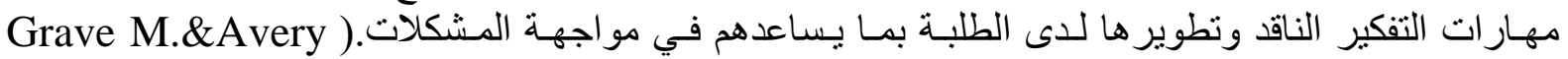


ومن مهار ات التفكير الناقد المستخدمة في هذا البحث:

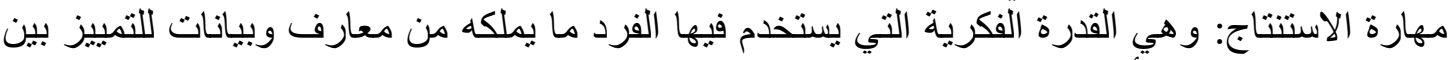

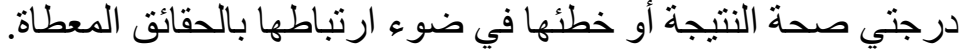

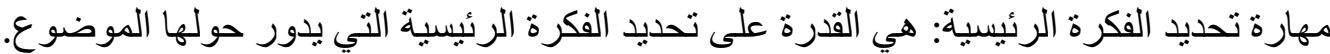

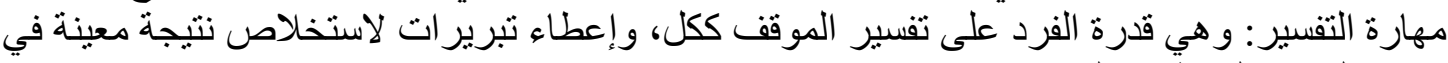

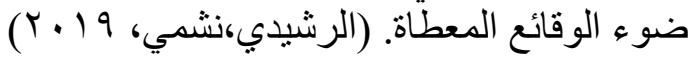

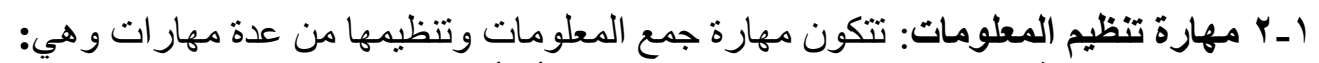

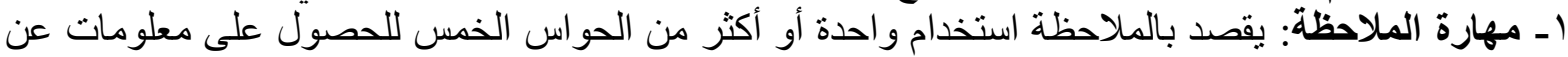

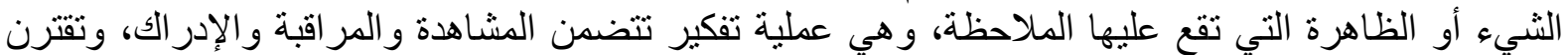

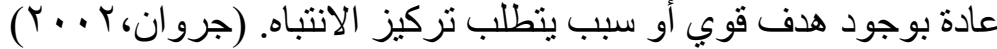

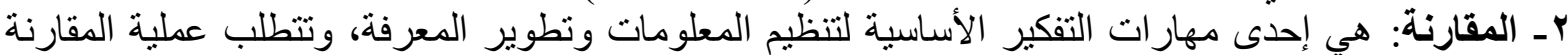

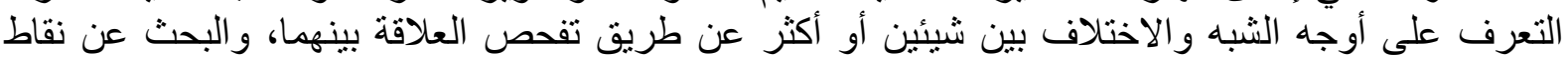

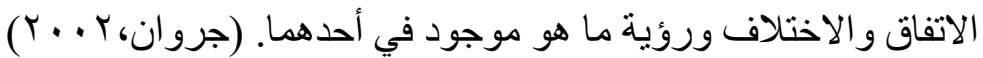

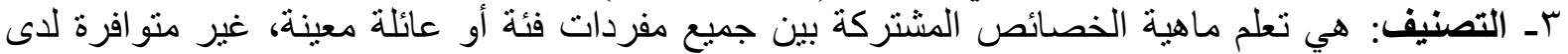

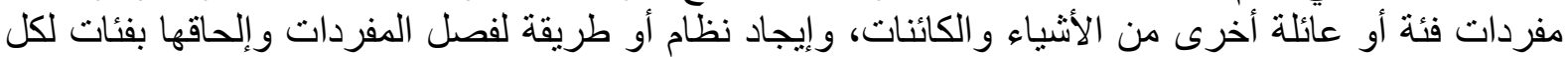

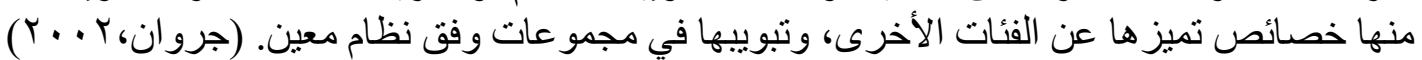

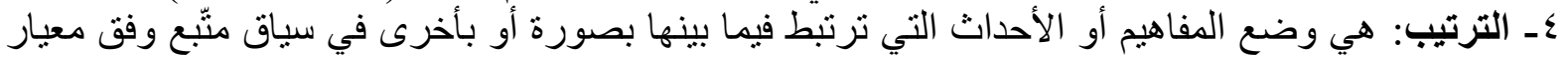

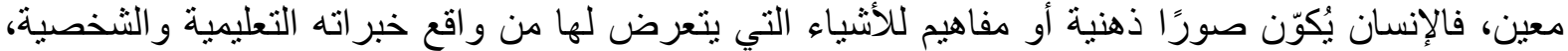

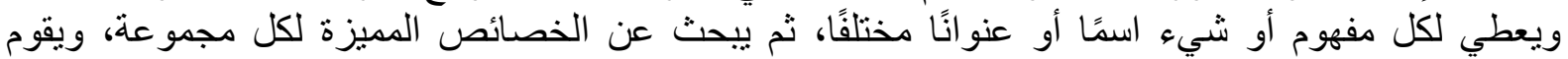

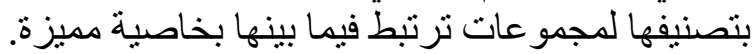
هـ تتظيم المعلومات: هي وسيلة لتنمية العقل وترتيب المعلومات بحيث بمكن أن يتوصل إلى المعلومة كلما أتيحت له فرص الرجوع إلى مصادر ها.

\section{1- المحور الثانى: أدوات التفكير:}

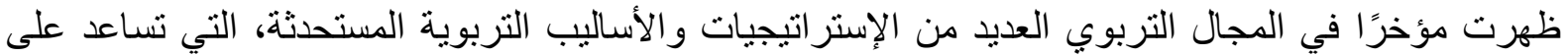

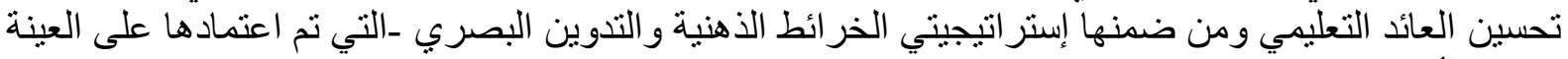

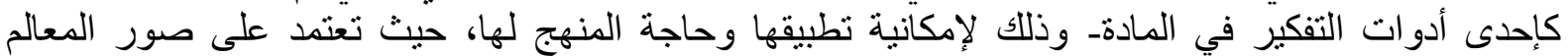
التاريخية ومقارنتها ببقية العصور، وتفسير العوامل التي أثرت على بنائها، وهذه الأدوات هي التي ستعتمدها

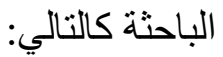

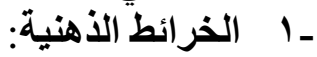

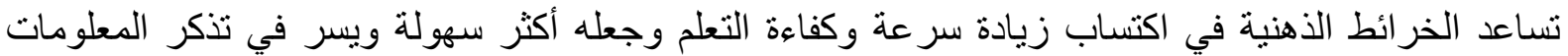

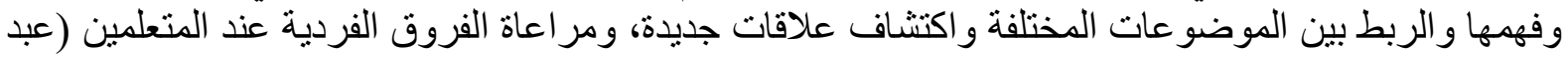

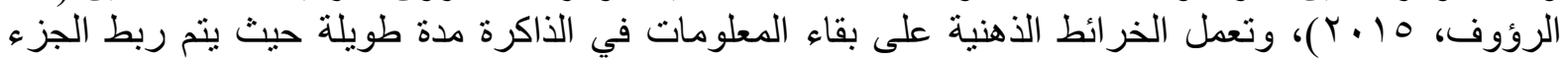

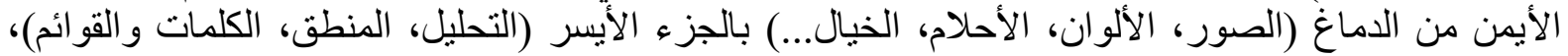

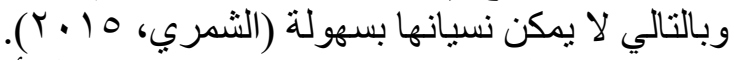

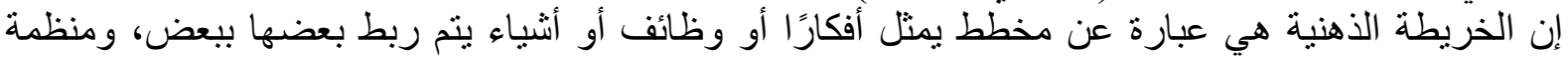

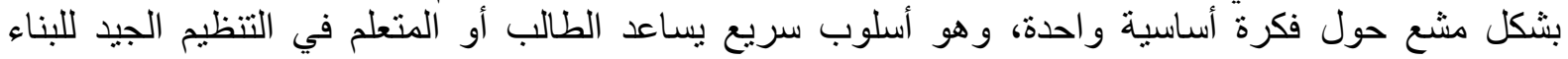

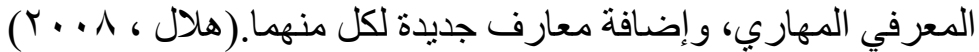
كما تعرف بأنها مجموعة وإف من الصور والرسوم التخطيطية المنظمة، التي تمثل رؤية الطالب للمادة الدراسية

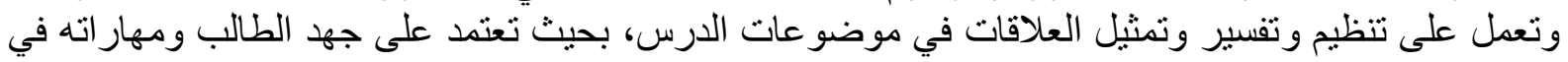

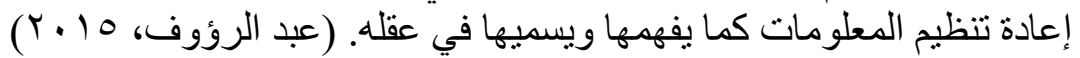

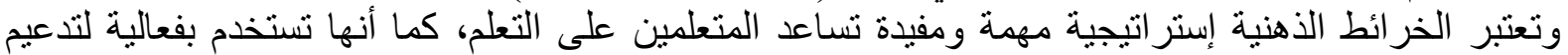

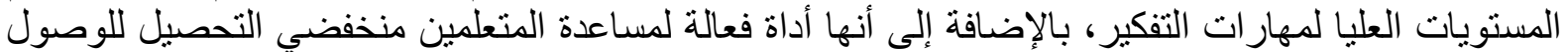

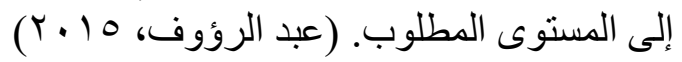


وحتى يصبح التدريس ذا قيمة يجب أن يشارك الطلبة في إعداد الخر ائط الذهنية بالطريقة التي تناسب شخصياتهم.

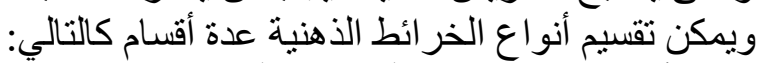
ـ ـ ـ أنواع الخرائط الذهنية من ناحية إعدادها:

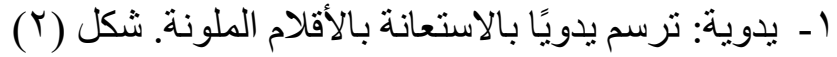

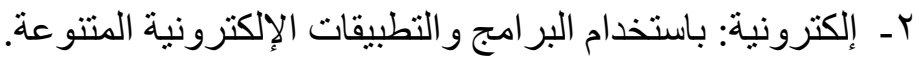

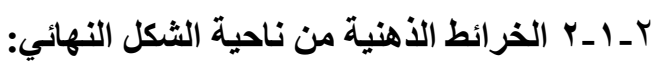

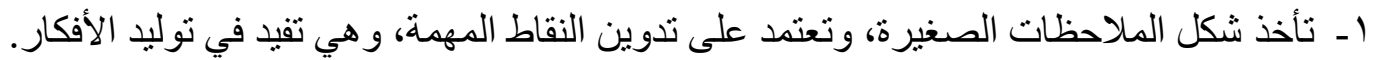

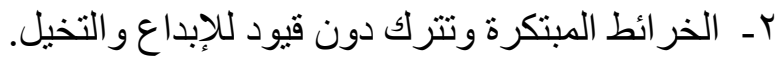

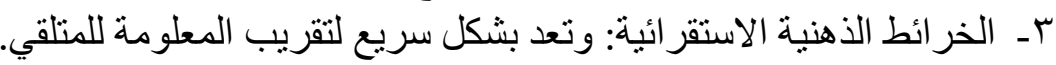
عـ ـ الخر ائط الذهنية العنكبوتية.

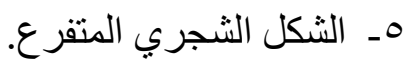
7ـ الأشكال التخطيطية العادية.

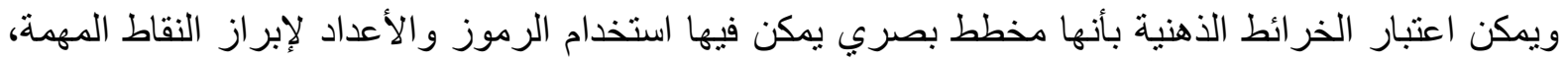

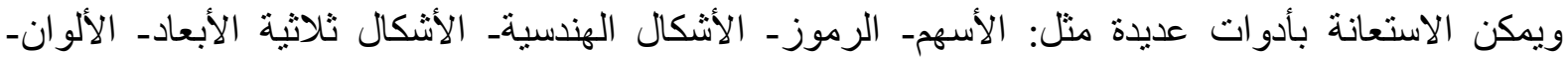

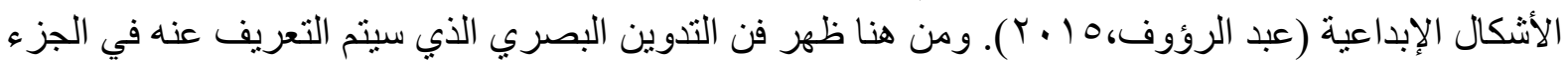
التالي.

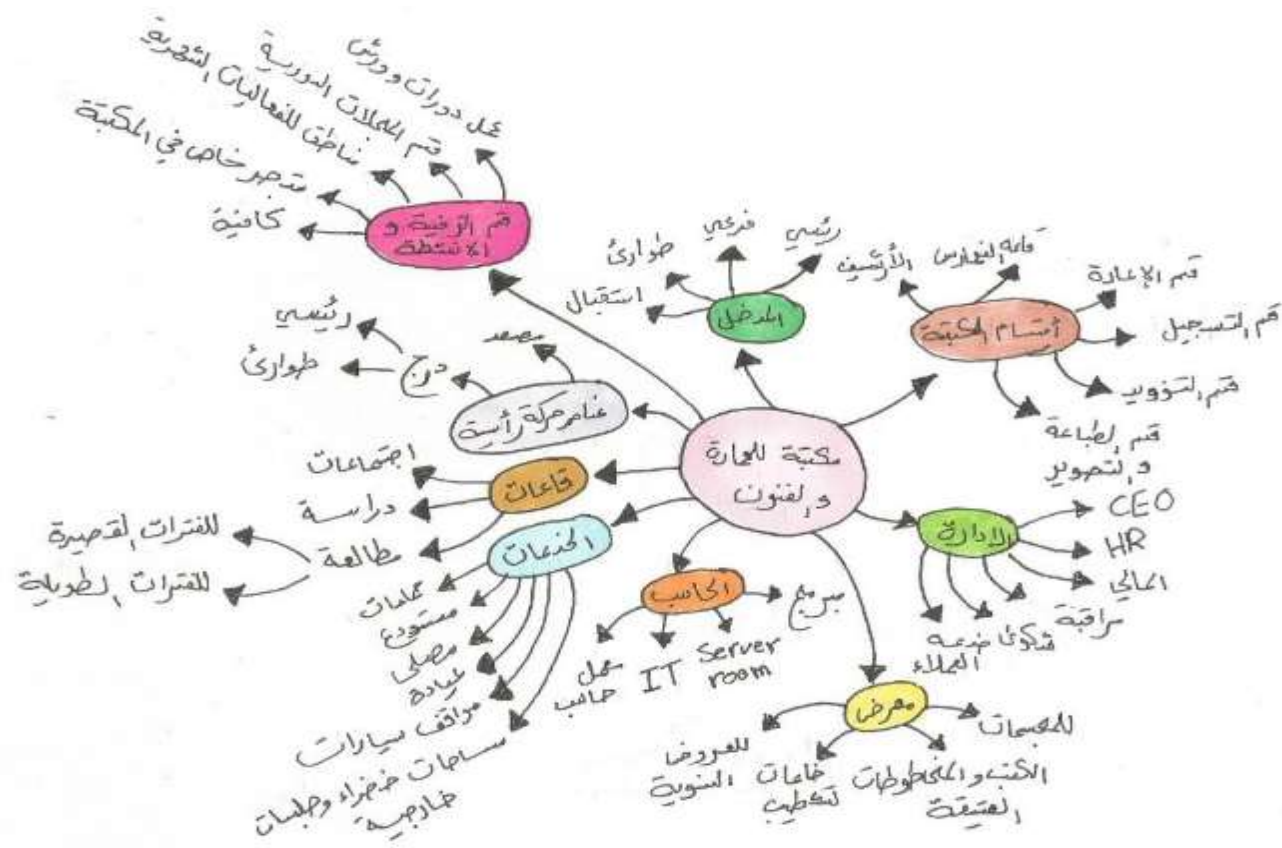

شكل(ץ) يوضح توظيف الخارطة الذهنية بمادة بحث تخرج

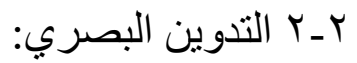

تعددت الأبحاث العلمية في مجال التفكير و علومه ومستجداته لخدمة طلبة العلم وترسيخ العلوم و الاستفادة منها في المجالات المختلفة، وقد ركز هذا البحث على بعض تطبيقات التفكير التي استعين بها في مجال التعليم، ومنها 


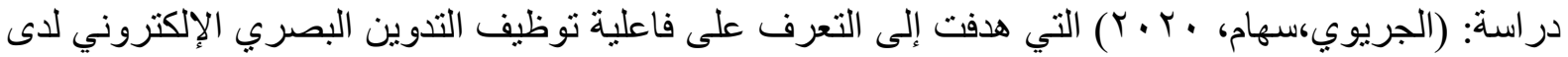

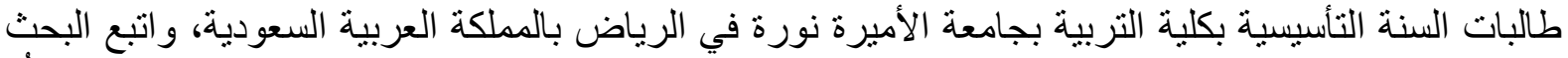

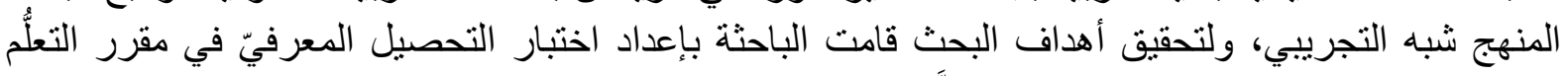

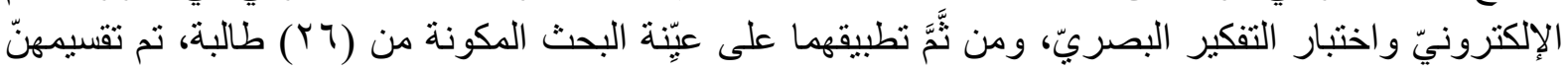

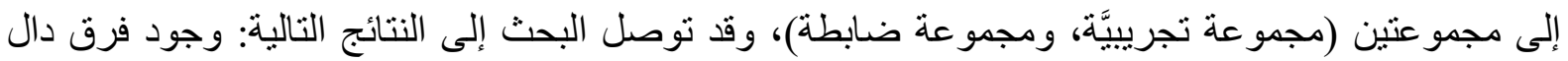

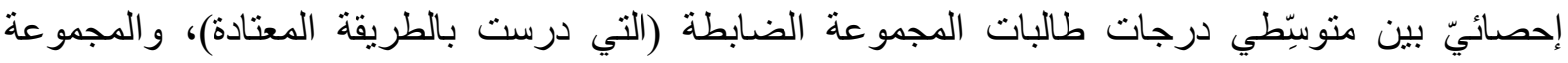

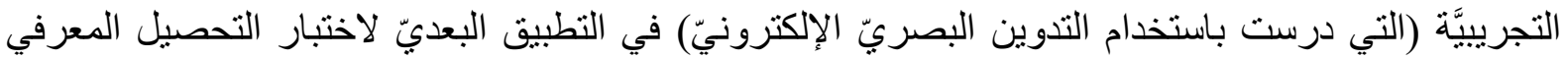

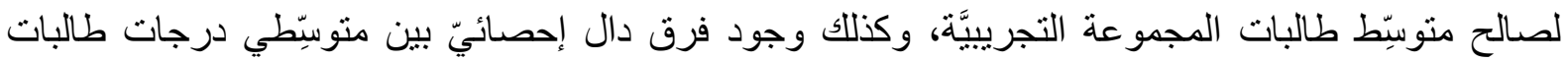

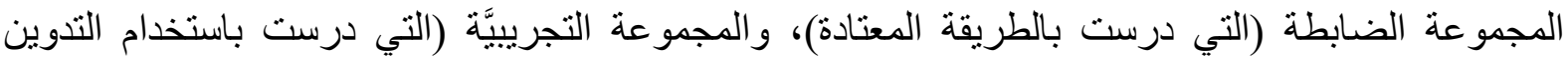

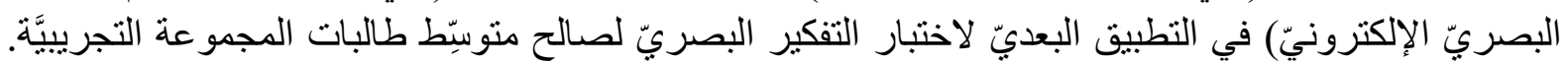

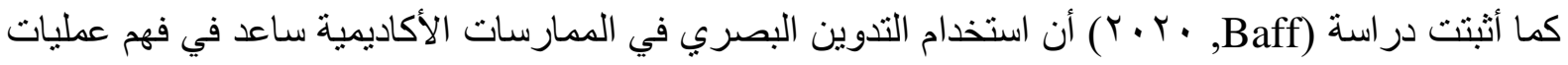

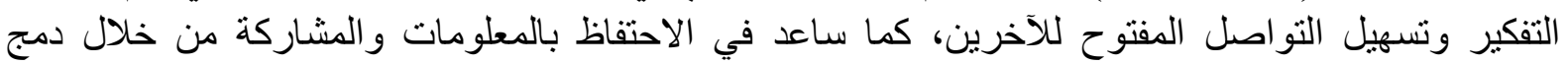
(Sketch notes)

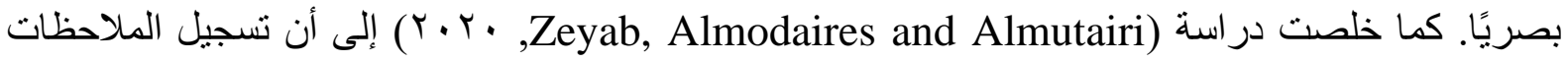
المرئية وما يُعرف بالتدوين البصري؛ دوبة هو تصور الأفكار المعقدة بتتسيق بسيط ومفهوم. ويمكن أن يدعم حل

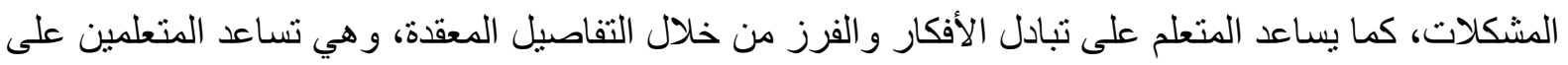

تطوير فهم أعمق للمعلومات الجديدة. يمثل أسلوب التدوين البصري في التدريس لمقررات التصميم وسيلة مهمة للبيئة التعليمية لقياس المهارات

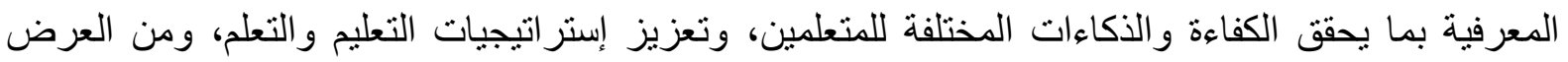

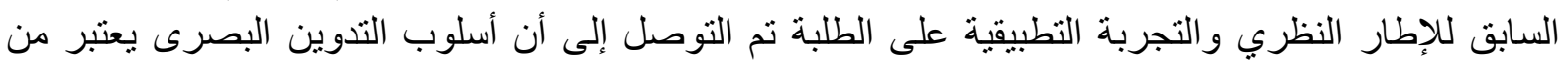
أساليب التدريس ذات الأهمية التي تعمل على تنمية المهارات المعرفية لدى الطالبات، وتعزز البيئة التعليمية بشكل يثرى عملية التعلم لمقرر ات التصميم. ويتم ذلك عن طريق مزج الرسومات مع الكتابة والأشكال لتدوين المعلومات المهمة بشكل بسهل حفظها

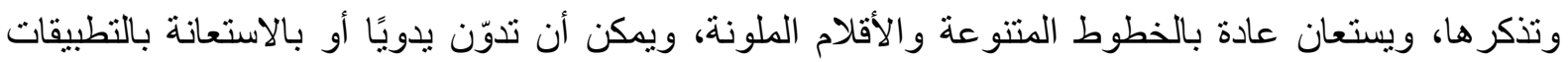

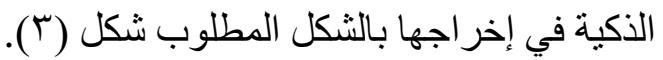

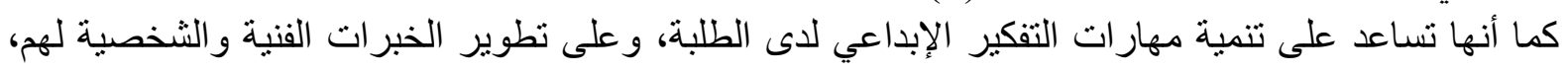
وانخراطهم في العملية التعليمية؛ لخروجها عن الطريقة التقليدية التي تكون عن طريق التهاية التدوين بالكتابة فقط

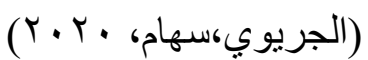

وبالتالي فيمكن توضيح النتائج المرتبطة بالإطار النظري و التطبيقي للبحث من خلال النقاط التالية:

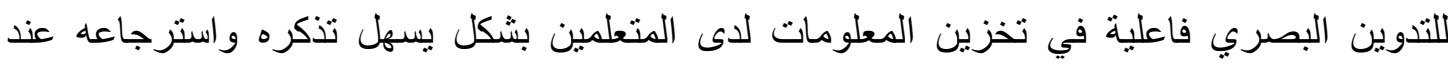
الحاجة. للتدوين البصري فاعلية في حث ذكاءات مختلفة عند المتعلمين و العمل على إبراز كل منها طبقًا للفروق الفردية. يساعد التدوين البصري على تحسين جودة التعليم من خلال ربط المحتوى التعليمي برموز مرئية تساعد على التعلم من خلال تفسير المحتوى بصريًا. يمكن أن يساعد أسلوب التدريس بالتدوين البصري في في دمج الأفكار و المحتوى النظري وتسهيل ربط

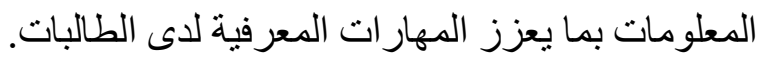




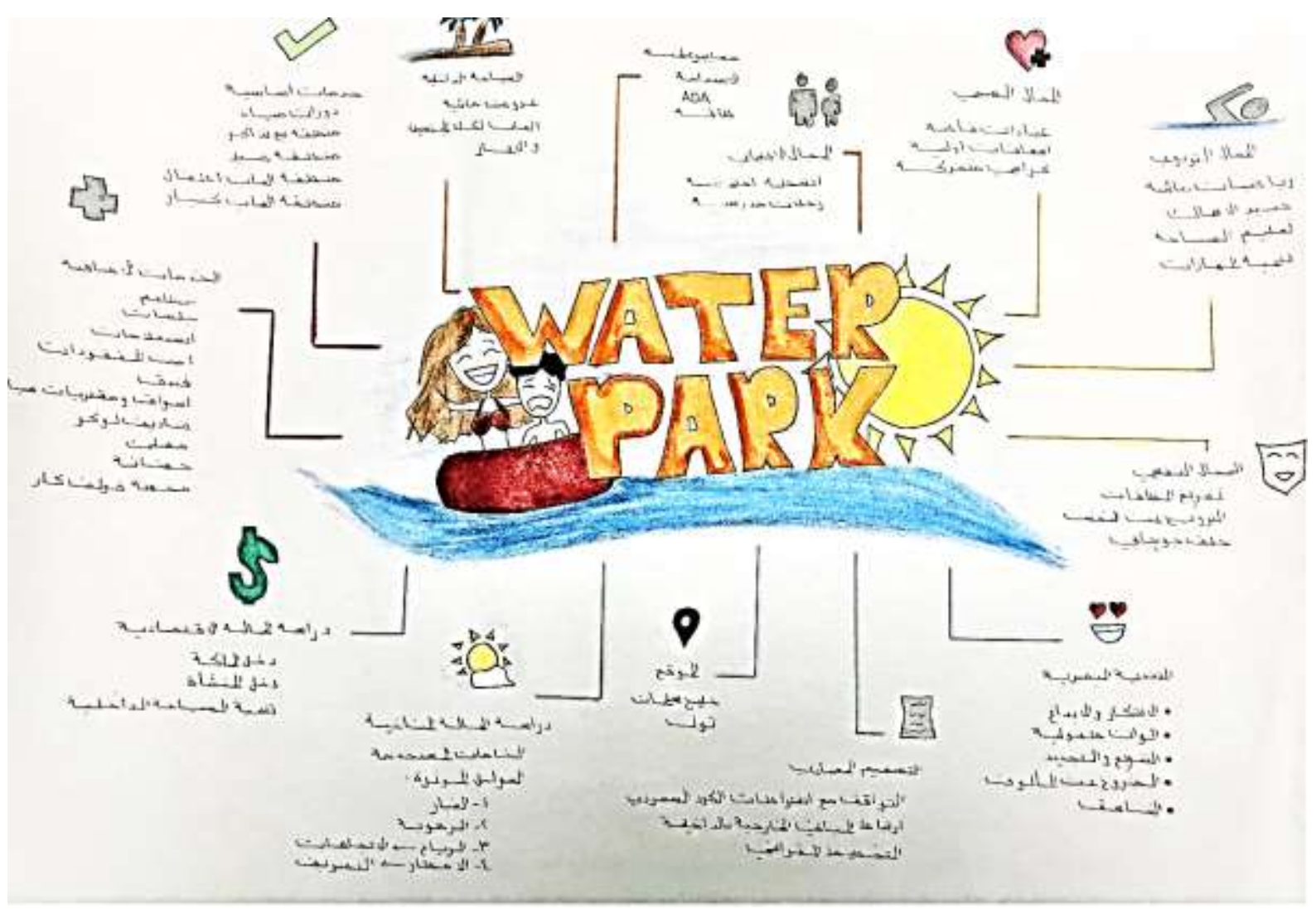

شكل () يوضح استخدام أداة التدوين البصري بمادة بحث تخرج

\section{r- المحور الثالث: التطبيق العملى}

بما أن المادة تعتمد بشكل أساسي على عرض الصور و الفيديوهات، ومناقثنة العناصر المعمارية، ومعرفة أثر الثرار

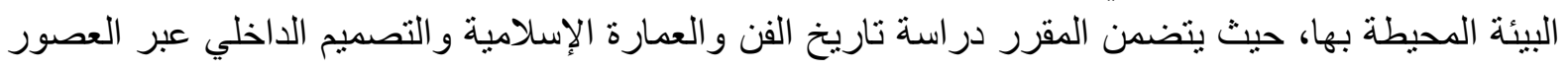

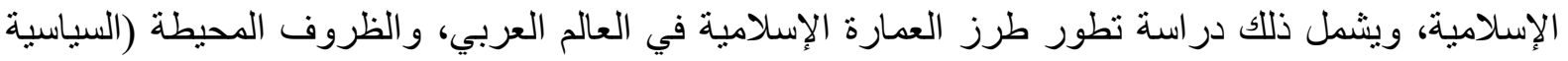

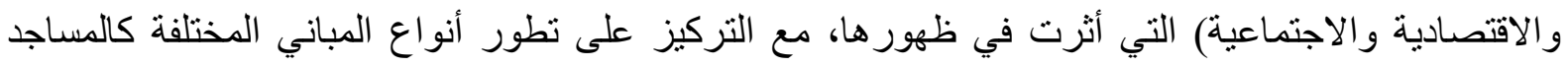

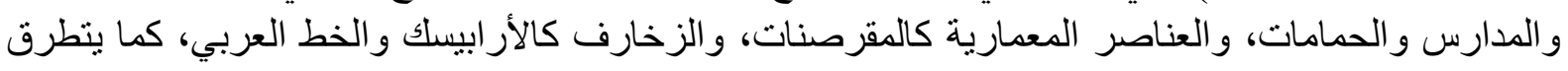

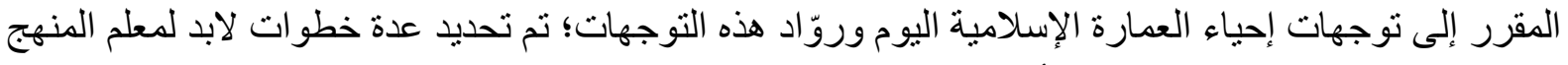
إجراؤها للوصول إلى نتائج تطبيق أدوات التفكير المناسبة لمناهج مادة تاريخ الفن والعمارة الإسلادية، وهية وهي

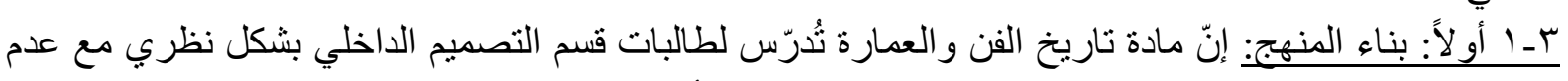

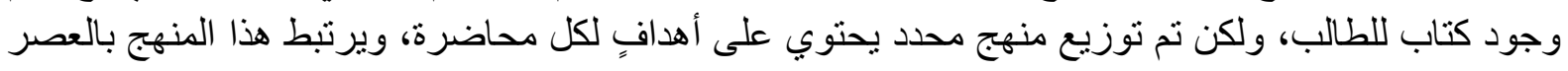

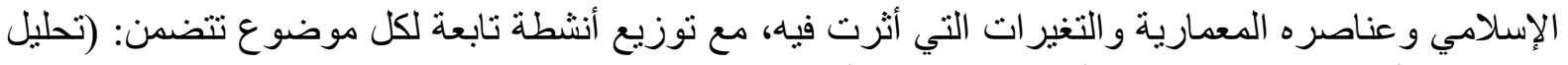

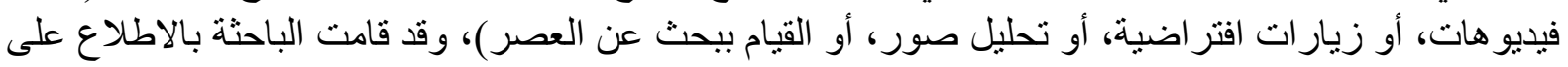

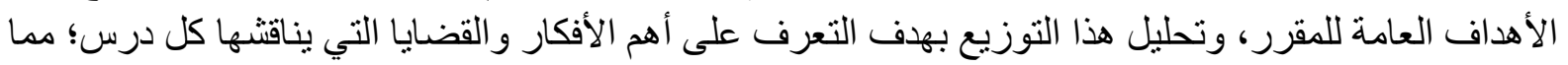




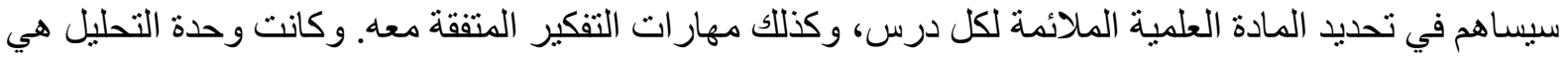

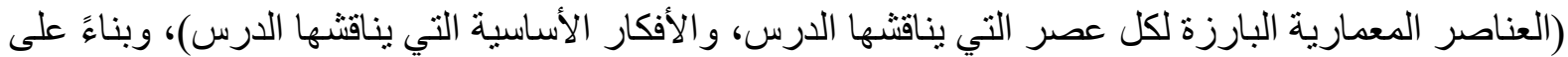

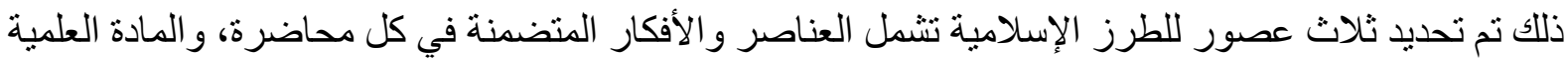
التي تتلاءم معها، وكذلك بعض الأنشطة المثيرة لتفكير الطلبة.

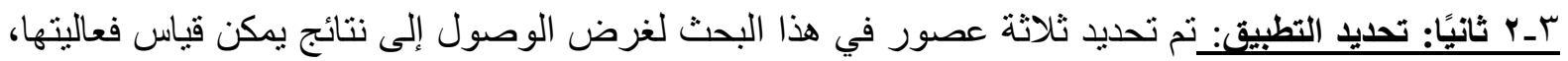

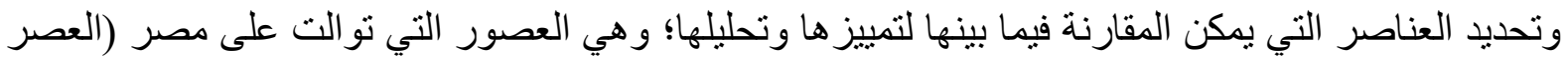

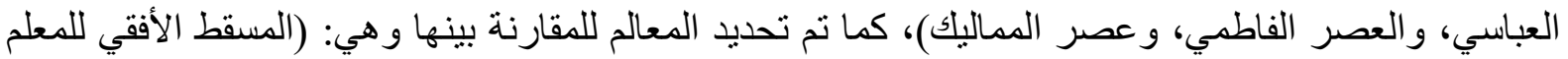

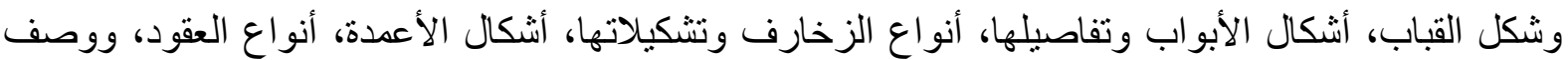

_L بالثًا: إعداد الإستر اتيجيات المقترحة:

قامت الباحثة بوضع الإستر اتيجية المقترحة بناءً على مهارتي التفكير الناقد ومهارة جمع المعلومات وتنظيمها

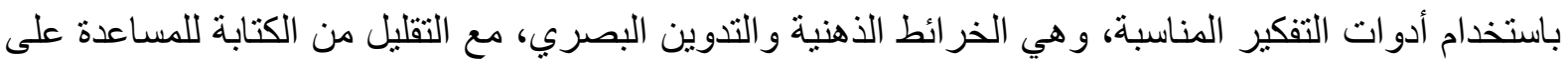

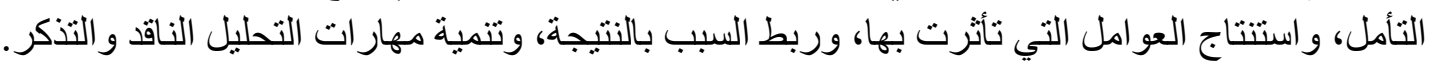

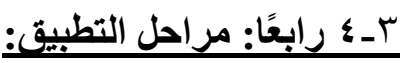

ا. خلال الزيارة الميدانية أو الافتر اضية: في حال تعذر الزيار ات الميدانية يعرض المعلم صورًا وفيديوهات

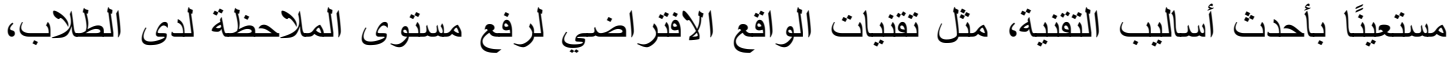

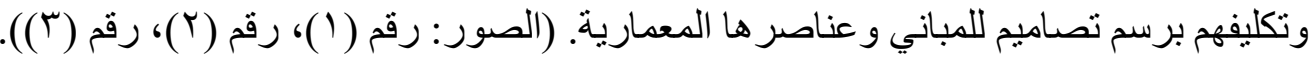
Y. خلال المحاضرة: يقوم المعلم بعمل نموذج توضيحي للطلبة على لوح التدريس بالاستعانة بالخرائط

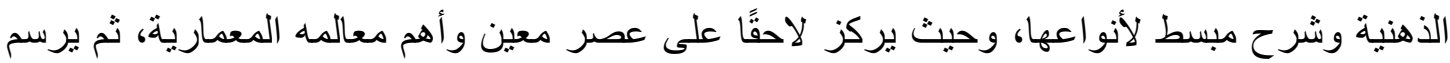

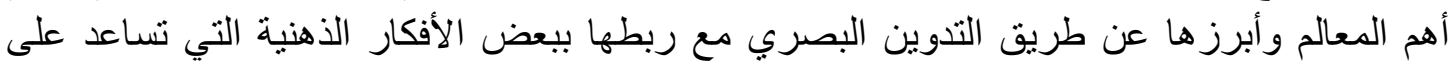
التذكر و الفهم، لتحفيز الطلبة على التفكير. ץ. يقوم المعلم بعقد مقارنات لإحدى المعالم التاريخية وتفاصيلها المعمارية وتغيّراتها عبر العصور عن طريق التدوين البصري.

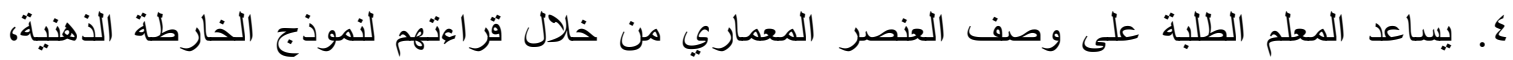

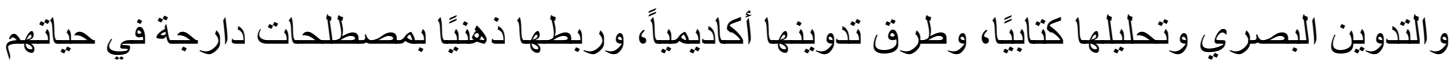

$$
\text { اليومية (غير علمية) تساعدهم على التذكر و الاستيعاب. }
$$

ه. بطلب المعلم من الطلبة تمرينًا منزليَّا لرسم الخرائط الذهنية الخاصة بهح بالاستعانة بهذه التقنيتين

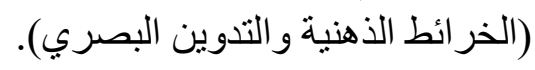

التمرين المقترح للتطبيق: يكلف الطلبة بعمل مقارنة بين العناصر المعمارية بين

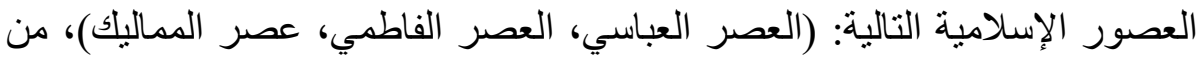

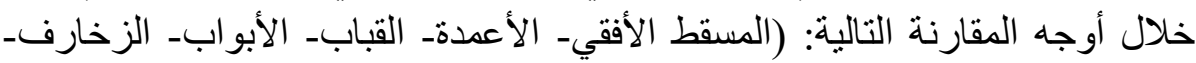

$$
\text { العقود) (سيتم عرض النتائج في جدولـ ( - ). }
$$

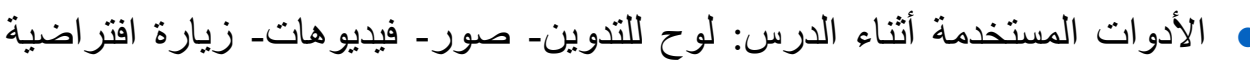

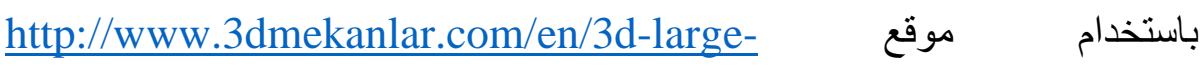


صور (1) نماذج من الصور المعروضة أثناء المحاضر ات

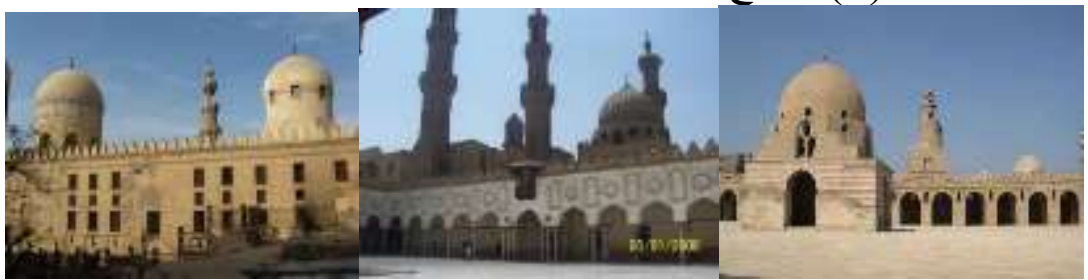

صور (Y) نماذج من الفيديو هات المقترحة

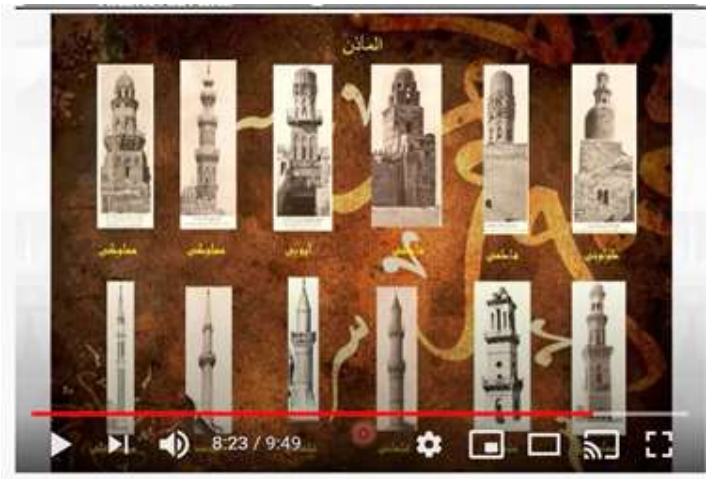

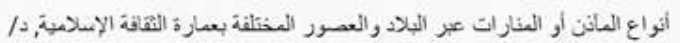

كمال الجبلارى

https://youtu.be/dqD-PbDtIEk

صور (T) من مو اقع الجو لات الافتر اضية

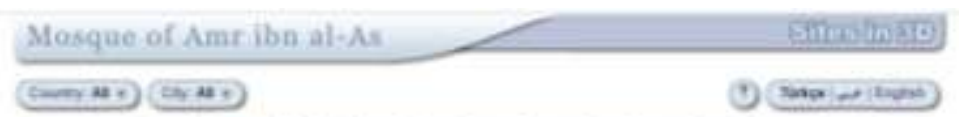

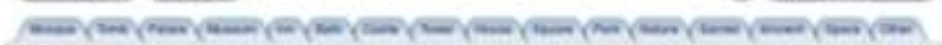
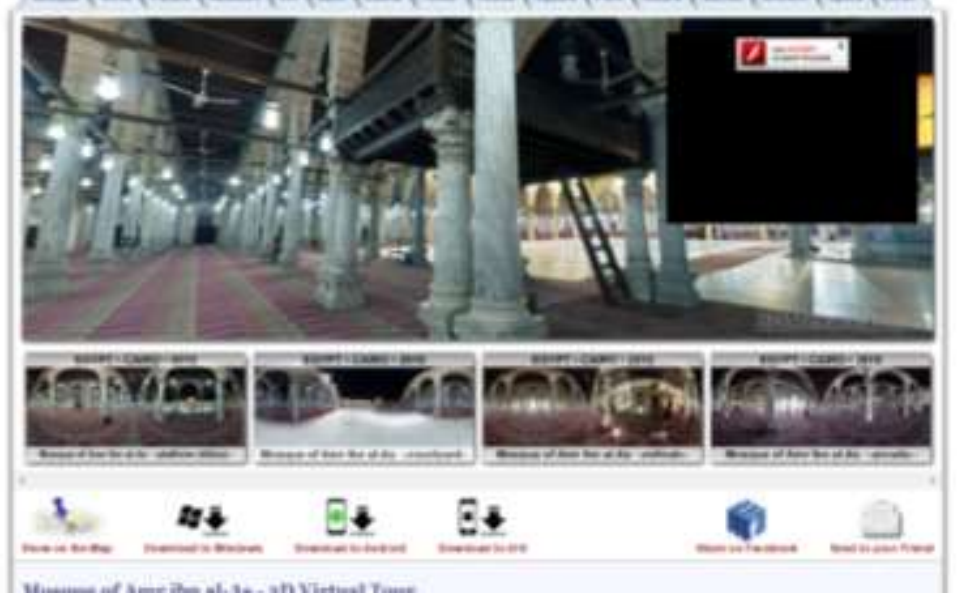

• التدريب على التدوين: في بداية الدرس يقدم المدرس نبذة عن العوامل الجغرافية والديموغرافية و التاريخية لمناطق العصر الذي سيتم التركيز عليه؛ وذللك لمساعدتهم على الربط واستتناج العوامل التي لبذه التي 
أثرت على العمارة في ذلك العصر، ثم يقوم بعرض الصور و الفيديوهات و الجو لات الافتر اضية، وخلالها يتم تحفيز الطلبة على تدوين ملحوظاتهم بشكل رموز أو كتابات بسيطة، وتزويدهم في في آخر المحاضرة

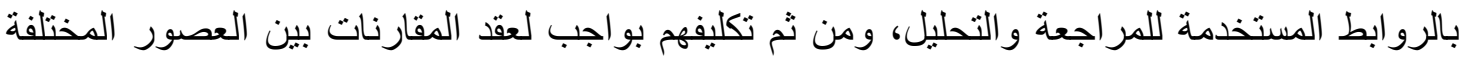
لتمييز الفوارق بينهم، مع ترك حرية التعبير عن العناصر بطريقة تناسبهم وتساعدهم على التذكر.

\section{r ــ خامسًا: نتائج تطبيق الطلبة لمهار ات التفكير وأدواته على المطلوب:}

بعد تطبيق التمرين يستلم المعلم من الطلبة نتائج التطبيق ويقوم بعرضها على بقية الفصل، ويترك للطالب الحرية

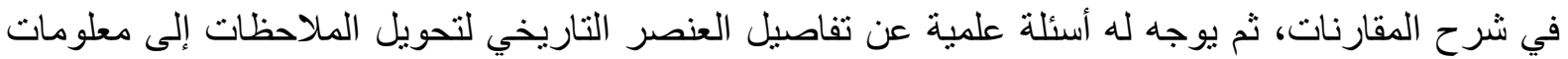

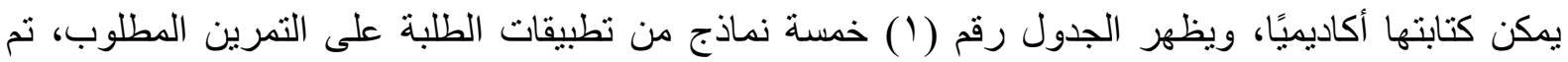

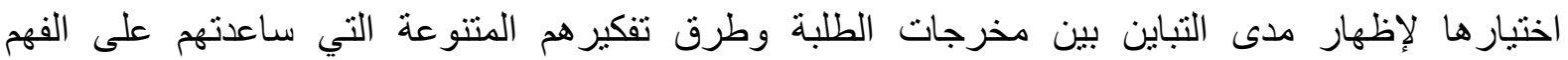

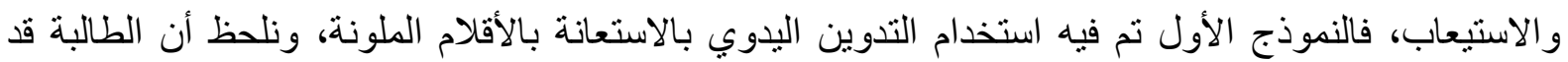

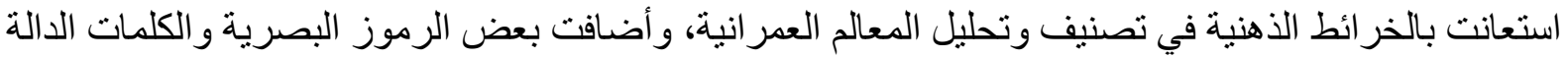

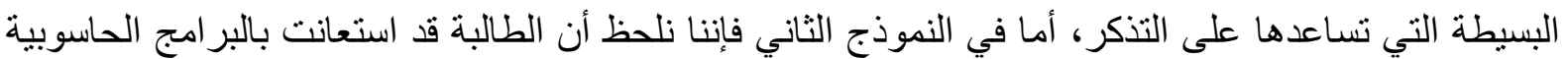

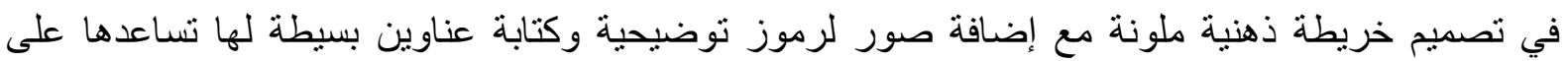

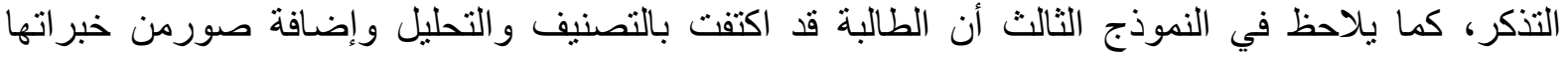

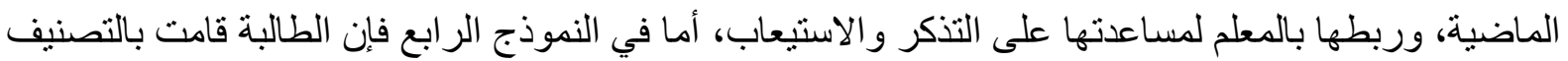

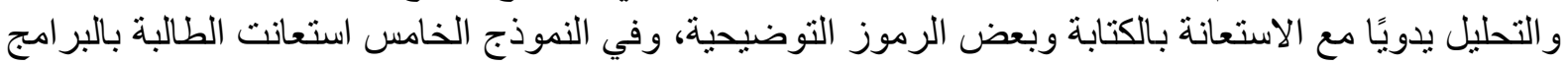
التقنية وبشكل كبير بالأيقونات و الرموز التي تربط المعلم بأدوات من حياتها اليومية. 


\section{جدول (1) يوضح التطبيقات العملية للطلبة}

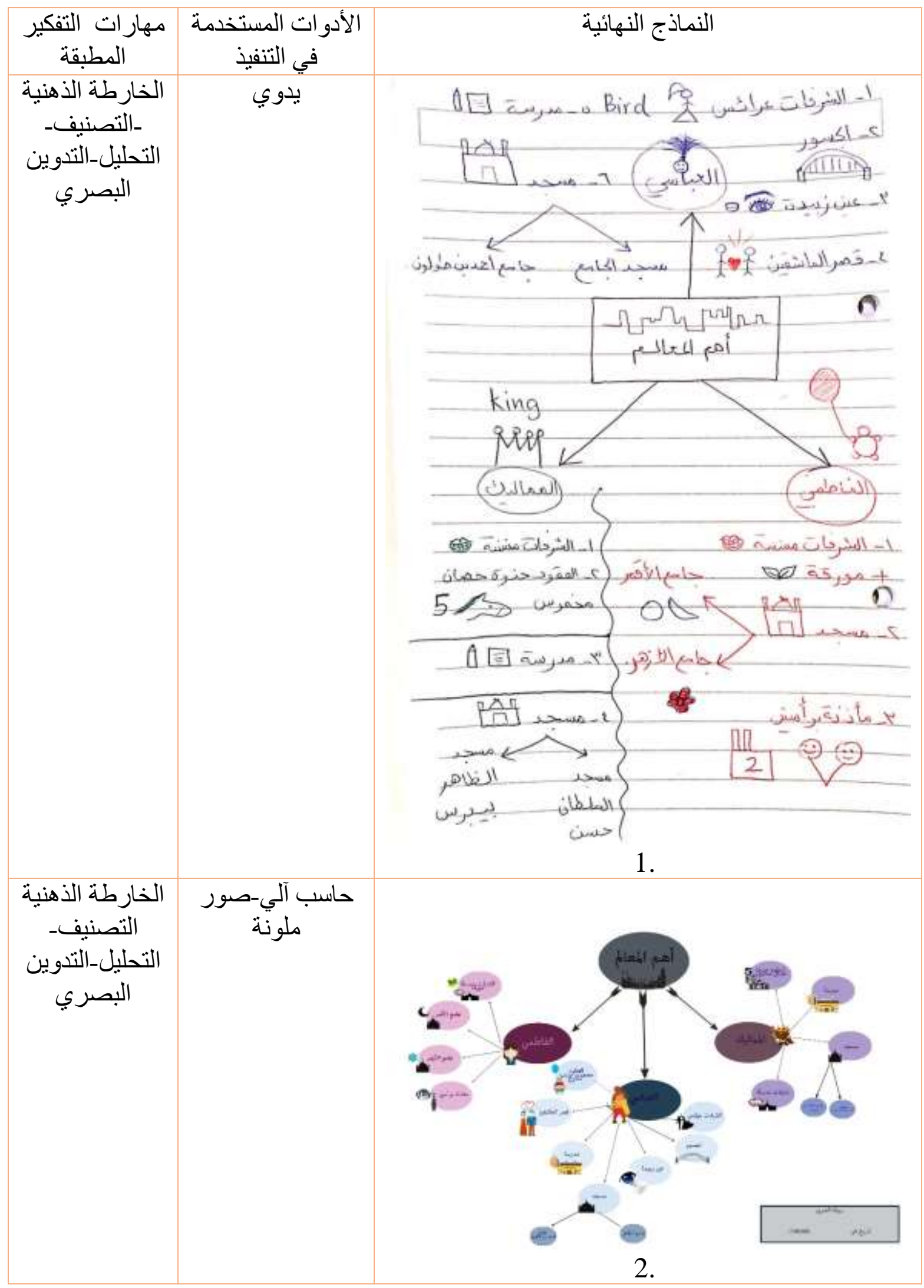




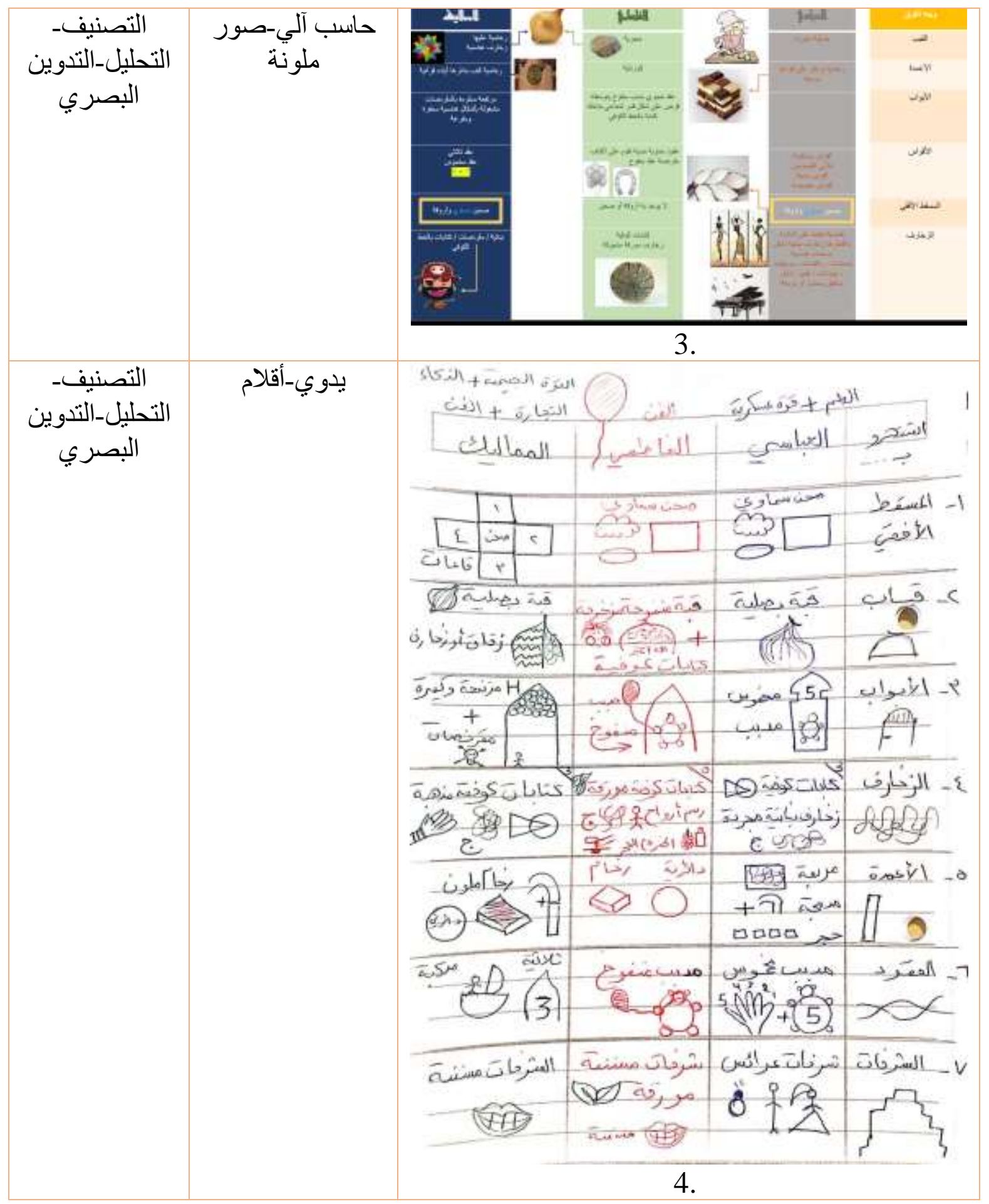




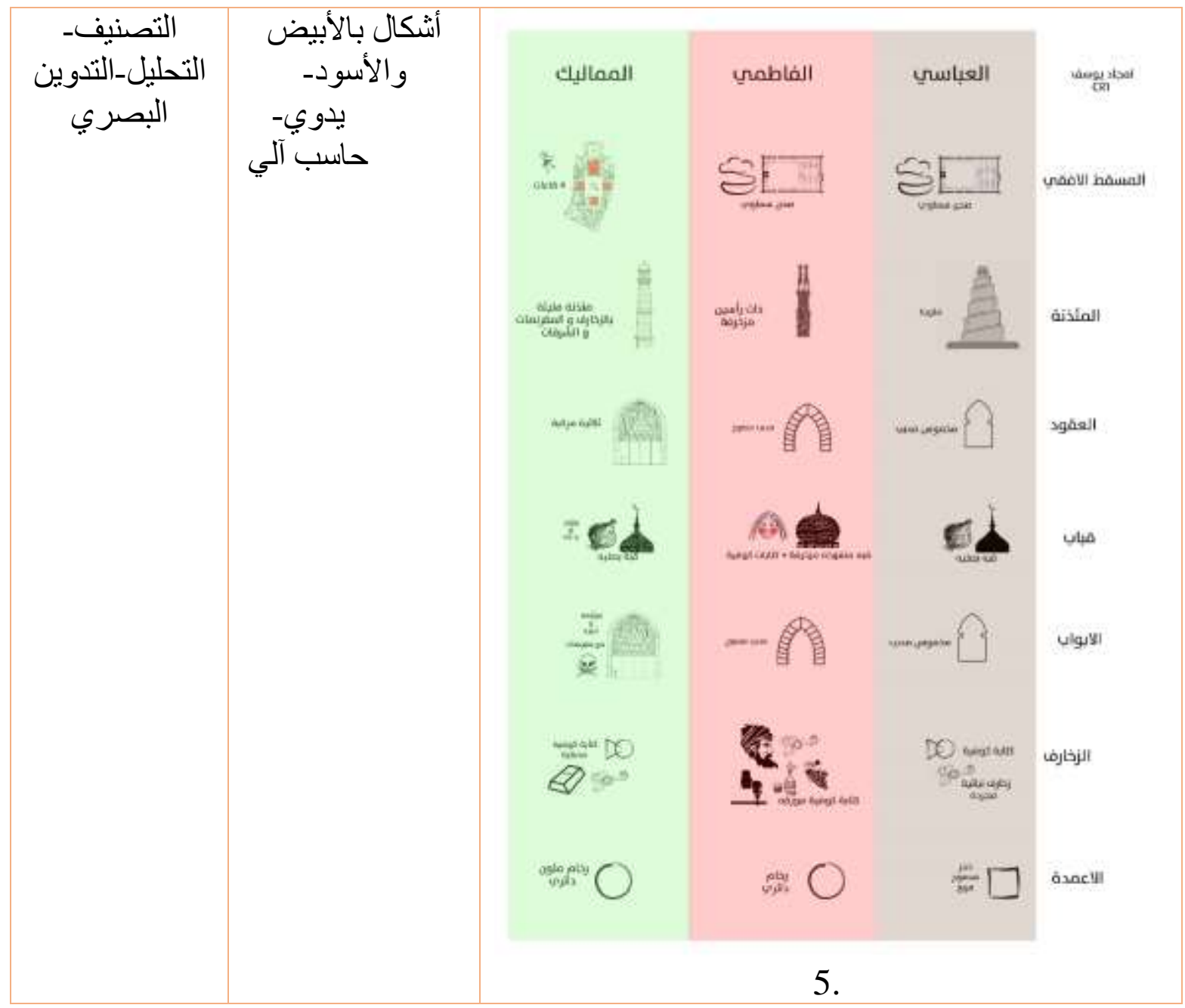

ـ ـ ـ ـادسًا: مناقشة نتائج التطبيق :

لتقييم فاعلية تطبيق مهار ات التفكير و أدواته على العينة تم تقييم الطلبة باستخدام الاختبار النظري، وذلك بعرض الته

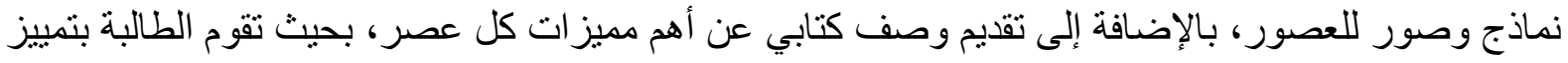

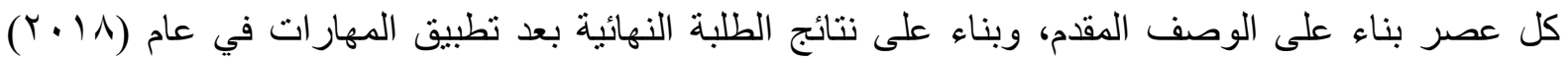

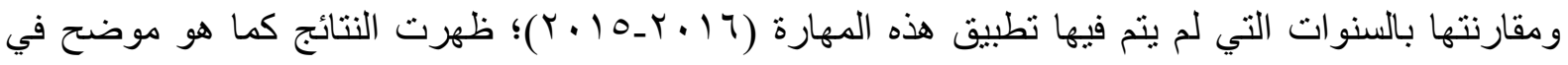
الشكل التالي : 


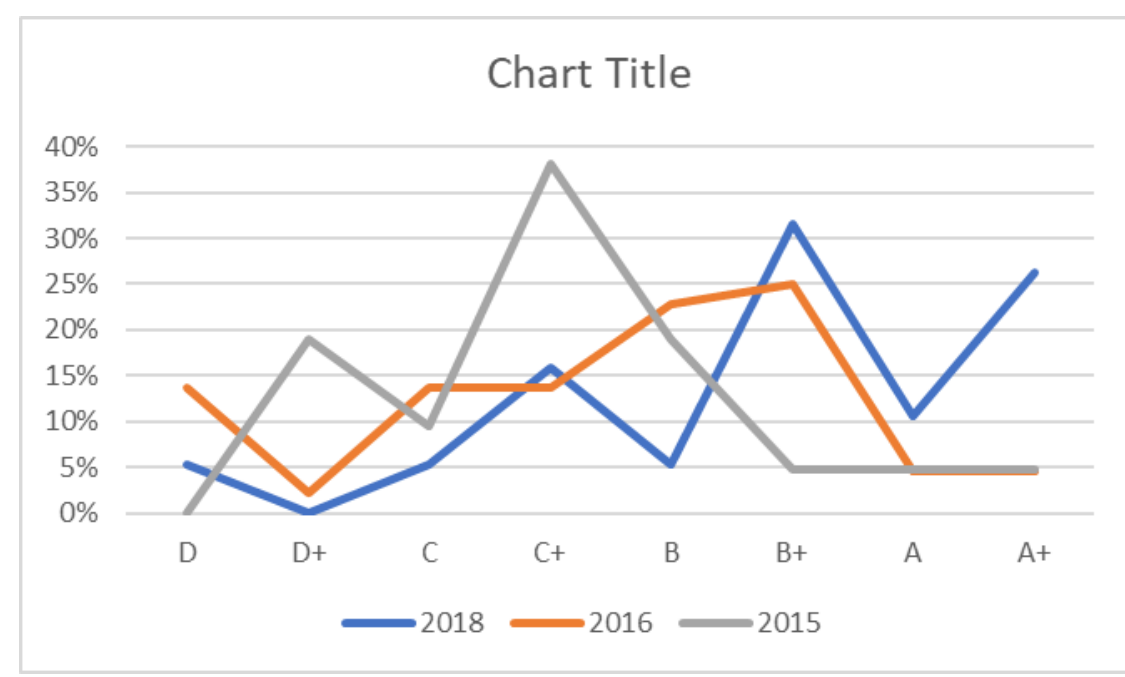

\section{شكل (ع ) يوضح نتائج الطلبة خلال أعوام الدراسة}

نلحظ من الجدول السابق أن هناك فروقًا ذات دلالة إحصائية إيجابية في الاختبار المعرفي لتقييم الطالبات

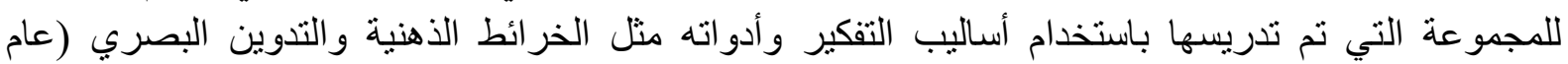

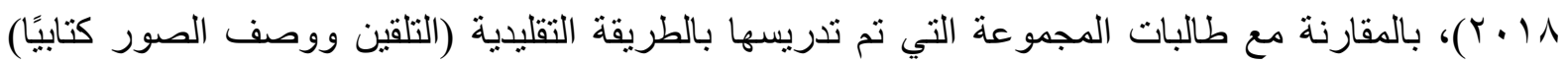

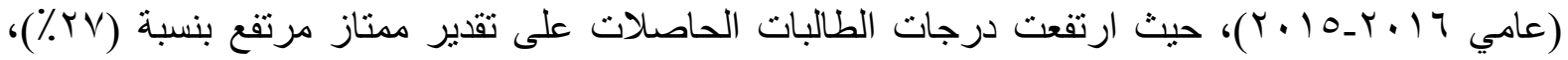

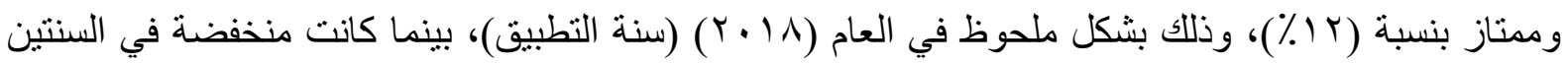

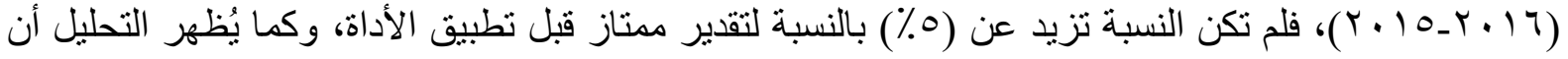

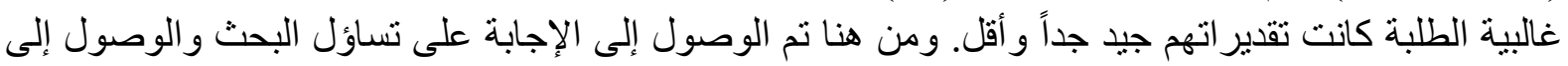
النتائج المرجوة. نتائج البحث:

ترى الباحثة أن تحسّن نتائج الطلبة لاى عينة البحث التجريبية يرجع إلى الأسباب الآتية :

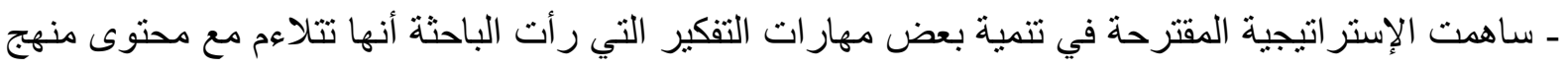

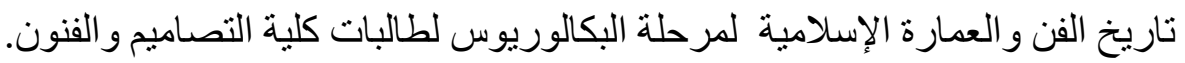

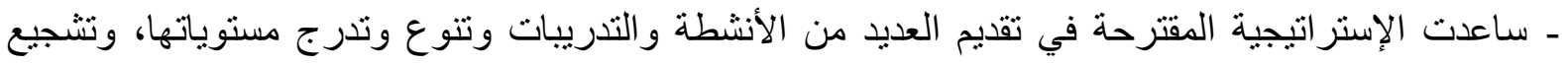

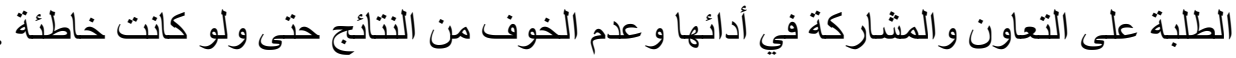

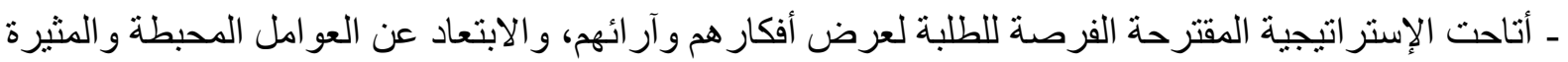

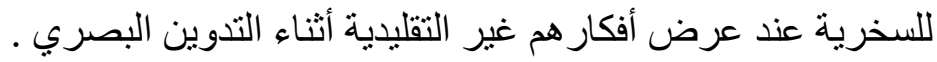

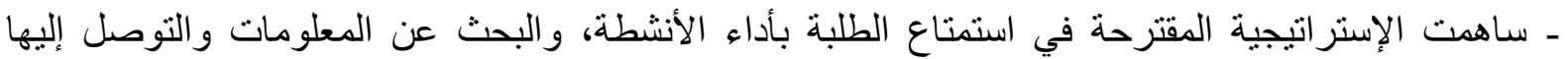

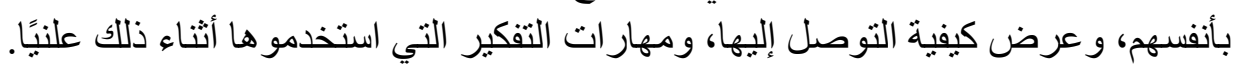
- وضحت الإستر اتيجية المقترحة للطلبة مدى الارتباط بين مضدمون المحتوى وفكرة تصميم المعلم التاريخي،

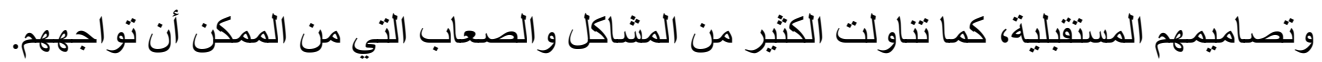

الخلاصة: - (الخت

أثتتت الدراسات التربوية فاعلية تطبيق مهارات التفكير على تحسين أداء الطلبة، وهذا البحث يركز على مدى ألى

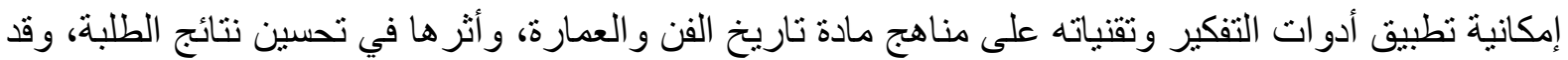

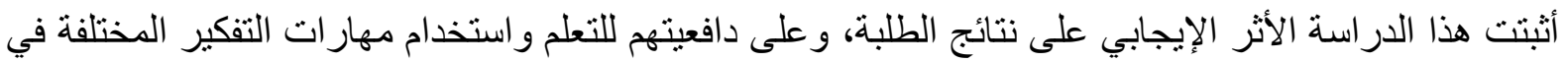

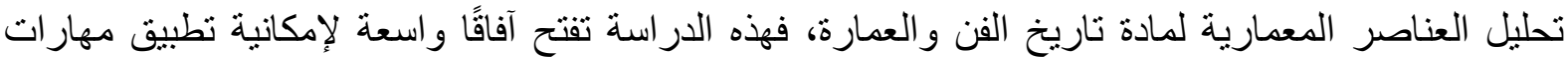


التفكير و أدواته المتنوعة في جميع مناهج كليات التصاميم والفنون، وتدعو إلى ضرورة تضمين المناهج لهذه

$$
\text { في ضو ء ما أسفرت عنه النتائج يوصي البحث بما يلي: }
$$

ـ ضرورة الاهتمام بتدريب الأساتذة على استخدام استر اتيجيات التفكير في تدريس مواد ومناهج التصاميم

ـ ضرورة الاهتمام بتدريب الطلبة على التفكير، والبحث والتنقيب عن المعلومات، وتنظيمها بدلاً من

إعطائها جاهزة للطلبة.

ـ ضرورة الاهتمام باستخدام استر اتيجيات التفكير في تدريس مناهج التصاميم و الفنون في المرحلة الجامعية

حيث أوضح البحث مدى ملاعمنها بالهام لها.

-ضرورة الاهتمام بتنمية مهار ات التفكير في مناهج التصاميم و الفنون و التي تعطي حرية للطالب بالبحث

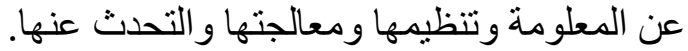

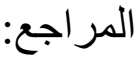

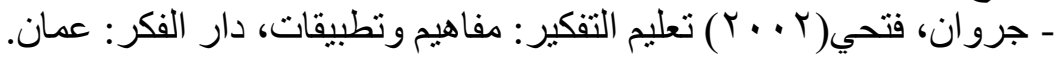

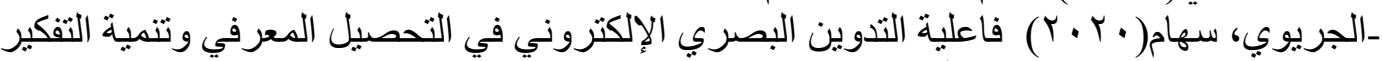

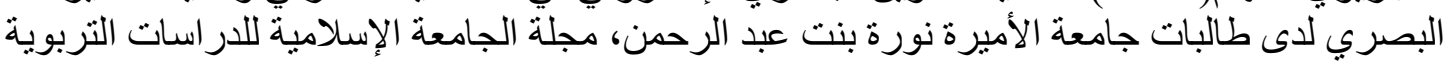

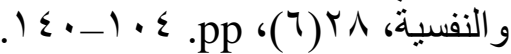

ـالرشيدي، نشمي(9 1 ـ ب) فاعلية محتوى إلكتروني تكيفي قائم على الأسلوب المعرفي (التحليلي،

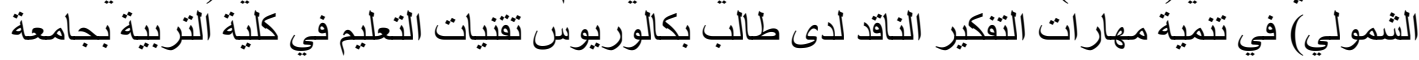

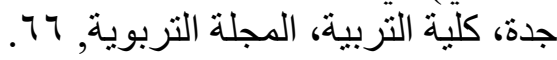

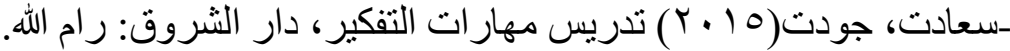

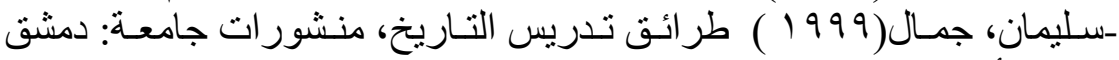

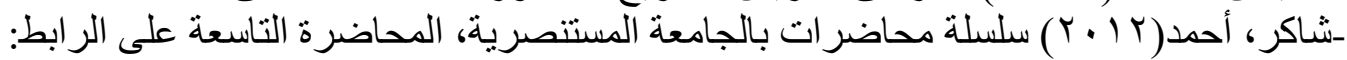
https://cutt.us/DO3KV

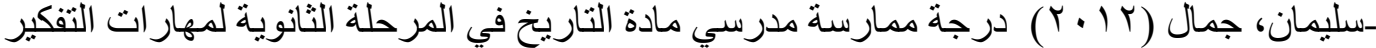

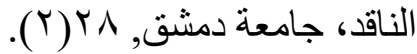

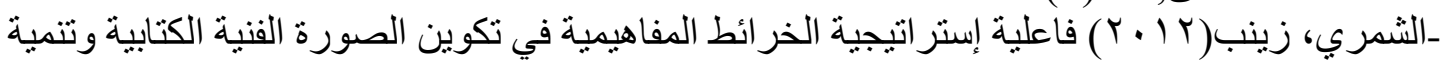

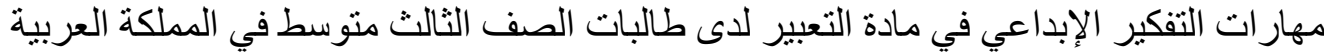

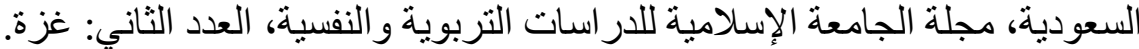

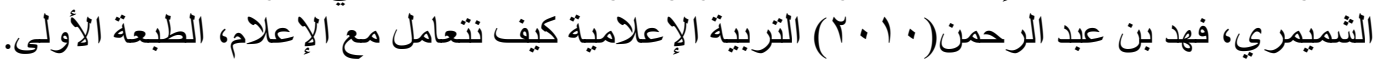

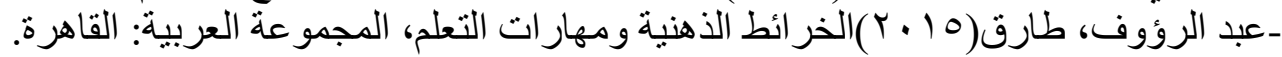

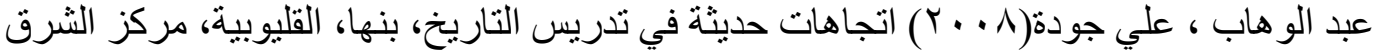

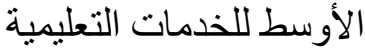

ـ هلال، محمد(1 . . ץ) مهار ات التفكير و التخطيط الإستر اتيجي، مركز تطوير الأداء و التنمية: مصر.

- Grave M. \& Avery,P.(1997): Scaffolding students reading of History. The social studies,88(3) - Baff, D. (2020) 'Using Sketchnotes in PhD Research and Academic

Practice', International Journal of Management and Applied Research, 7(3), pp. 370381.

- Zeyab, A., Almodaires, A. and Almutairi, F. (2020) 'Thinking Differently: A Visual

Note Recording Strategy to Improve Learning', Journal of Education and Practice.

doi: 10.7176/jep/11-2-02.

- http://www.3dmekanlar.com/en/3d-large-mosques.html

- https://youtu.be/dqD-PbDtIE 